\title{
Status and the Demand for Visible Goods: Experimental Evidence on Conspicuous Consumption
}

\author{
David Clingingsmith ${ }^{\mathrm{a}, *}$ \\ Roman M. Sheremeta ${ }^{\text {a,b }}$ \\ ${ }^{a}$ Weatherhead School of Management, Case Western Reserve University \\ 11119 Bellflower Road, Cleveland, OH 44106, U.S.A. \\ ${ }^{\mathrm{b}}$ Economic Science Institute, Chapman University \\ One University Drive, Orange, CA 92866, U.S.A.
}

December 4, 2015

\begin{abstract}
Some economists argue that consumption of publicly visible goods is driven by social status. Making a causal inference about this claim is difficult with observational data. We conduct an experiment in which we vary both whether a purchase of a physical product is publicly visible or kept private and whether the income used for purchase is linked to social status or randomly assigned. Making consumption choices visible leads to a large increase in demand when income is linked to status, but not otherwise. We investigate the characteristics that mediate this effect and estimate its impact on welfare.
\end{abstract}

JEL Classifications: C91, D03

Keywords: status, conspicuous consumption, experiment

* Corresponding author: David Clingingsmith, E-mail: dlc43@ case.edu or david.clingingsmith@ gmail.com We thank Yan Chen, Ori Heffetz, David Huffman, John List, Tanya Rosenblat, Klaus Schmidt, Justin Sydnor, Lise Vesterlund, Alistair Wilson, Bart Wilson and seminar participants at Case Western Reserve University, Chapman University, Kent State University, the University of Michigan, the University of Pittsburgh as well as participants at the North American Economic Science Association Meetings in Dallas for helpful comments. We also thank the Weatherhead School of Management for generous funding of this project and Sarah Mattson for excellent research assistance. The usual disclaimers apply. 


\section{Introduction}

Social status refers to the hierarchical position an individual occupies in society. Social status is related to an individual's attributes, such as intelligence, creativity, beauty, affiliation, or family of origin, either through the returns such attributes earn in economic activity or the esteem in which they are held by society, or both. ${ }^{1}$

Veblen argued that social status has a profound influence on a person's consumption decisions. His book The Theory of the Leisure Class contends that status concerns affect the consumption choices of anyone whose income places them above the level of subsistence (2009 [1899]). Social conventions specify a minimum standard of clothing, food, and living conditions that are acceptable for each status level. Since social status and income are positively correlated, the acceptable standard of consumption for those of higher status includes more and better goods than for those of lower status. According to Veblen, an important function of consumption is to signal high status to others. Consumption choices can only do this to the extent they are both visible to others and associated with high status. Part of the motivation for wearing a fine suit or driving a luxury car, both of which are visible to others, is to convey the message to others that one has high status.

Consumer goods vary in the degree to which the act of consuming them is visible to the public, and thus in their suitability for serving as public markers of status. Many people see us when we are in our cars, when we wear our work clothes, or when we eat at a restaurant. Far fewer

\footnotetext{
${ }^{1}$ See a more detailed discussion at http://www.britannica.com/topic/social-status.
} 
see our sleepwear, what we have for breakfast at home, or the brand of toilet paper we buy. ${ }^{2}$ Veblen termed status signaling via the acquisition and display of visible goods conspicuous consumption. ${ }^{3}$

A number of studies have presented evidence about the relationship between status and the consumption of visible goods (Ravina, 2007; Grinblatt et. al. 2008; Charles et. al., 2009; Heffetz, 2011; Kuhn et al., 2011). However, there are several difficulties in identifying conspicuous consumption as a motivation for consuming visible goods. First, visibility is only one of many properties possessed by any given good that contribute to the observed demand for it. It is difficult to disentangle demand for visibility from demand for these other properties. While we may conjecture that a person buys a Mercedes rather than a Toyota to signal high social status, a Mercedes is a superior car in many ways besides the signal it sends about status. A second, subtly related problem is the link between income and social status. Income has effects on consumption that are independent of any status motivation. Observed correlations between status and consumption could be pure income effects. Income also tends to be correlated with various characteristics that confer social status through popular esteem, such as intelligence, education level, family background, profession, and political clout. Lastly, it is difficult to disentangle conspicuous consumption from social learning as factors that drive individuals with similar social status to make similar consumption decisions (Grinblatt et al., 2008).

We tackle the challenge of identifying conspicuous consumption by conducting a controlled experiment. In our experiment, individuals have an opportunity to purchase a desirable

\footnotetext{
${ }^{2}$ With the rise of social networks and associated technologies such as the smartphone, many formerly private choices, such as food consumed at home or the decoration of private spaces, have become increasingly visible to the public. Everyday millions of people post descriptions and images from their private lives on social networks such as Facebook and Instagram that feature the goods they consume.

${ }^{3}$ Several attempts have been made over the years to develop Veblen's ideas within a more formal microeconomic framework. Following Leibenstein (1950), some authors have mistakenly attempted to capture Veblen's argument with the notion that price is directly a part of utility. Veblen's analysis implies instead that the determinants of utility are consumption and social status in the eyes of others. Those goods which signal social status must be visible, but signaling may occur both through quantity and quality/price (Bagwell and Bernheim, 1996).
} 
consumer good: gourmet chocolate truffles. We independently vary both the visibility of consumption choices to others and whether the income available for consumption is linked to social status. ${ }^{4}$ After accruing income, each participant indicates their desired quantity of chocolate truffles for each of several potential prices. A common price at which sales are actually made is randomly selected from the potential prices at the end of the experiment.

We manipulate this process in two ways, using a two-by-two design. In the first manipulation, income is either assigned randomly or based on a participant's rank. A participant's rank is determined how well they do relative to the eleven other participants in their experimental session on a thirty-minute cognitive test. Our participants are students at Case Western Reserve University (CWRU). As at many elite universities, cognitive ability confers social status at CWRU. ${ }^{5}$ When income is assigned by rank it is directly correlated with status, but when it is assigned randomly it is unrelated to status. In the second manipulation, communication about the quantity of truffles purchased is either private, so that only the participant and experimenter know, or public, so that all participants in the experimental session can see how much each purchased. Participants know how their choices will be communicated before making them. We refer to the four treatments as rank-private, rank-public, random-private, and random-public.

Our design allows us to isolate the effect of visibility on demand since all other properties of the chocolate truffles are identical across the public and private treatments. We can also isolate the effect of the linkage between income and status. We can rule out social learning as a driver of

\footnotetext{
${ }^{4}$ Our study is related to a large literature on status signaling as a motivation for charitable giving and behavior in social dilemmas (Andreoni and Petrie, 2004; Soetevent, 2005; Andreoni et al., 2009; Ariely et al., 2009; Bracha and Vesterlund, 2013; Karlan and McConnell, 2014; Samek and Sheremeta, 2014, 2015). However, our use of a physical product as a status signal eliminates confounds present in previous studies. Buying chocolate provides only private benefit to the person who purchased it, while charitable giving and social dilemmas provide benefits to others as well. Our study therefore does not involve the confounding factors of generosity and altruism present in these other studies. ${ }^{5}$ While cognitive ability is a source of social status in general, it is particularly important in the social world of university students.
} 
consumption decisions within the experiment because our participants do not interact and have no information about the choices of others when they make their decisions.

Veblen's theory of conspicuous consumption predicts that demand will be higher in rankpublic than rank-private because when status is linked to income, visibility leads people to consume more to signal status. To the extent that by assigning income randomly we completely sever the link to status, Veblen's theory also predicts that demand will be the same in randompublic and random-private.

Consistent with these predictions, we find that making consumption choices publicly visible leads to a large increase in demand when income is linked to status, but not when income is assigned randomly. In other words, we find that the necessary conditions for conspicuous consumption are 1) for income to be correlated with status and 2) for consumption choices to be publicly visible to others. The effect is quite large: mean quantity demanded is 1.94 truffles in rank-private and 4.98 truffles in rank-public, an increase of $257 \%$. When income is unrelated to status, visibility does not induce conspicuous consumption: mean quantity demanded is 1.74 in random-private and 1.75 in random-public. Although our data provide support for a hypothesis that status is a significant factor motivating consumption of visible goods, the relationship between status level and conspicuous consumption is non-monotonic. ${ }^{6}$ Therefore, a person's income (and thus the social status) cannot be easily inferred from their actual chocolate choice in rank-public.

We find that gender and cognitive reflection are important mediators of conspicuous consumption. Men engaged in conspicuous consumption much more than women. Quantity

\footnotetext{
${ }^{6}$ We find that participants of moderately high and moderately low status engage in conspicuous consumption more than participants of middle status. Such non-monotonicities are possible in signaling games when players countersignal (Spence, 1973; Feltovich et al., 2002). This equilibrium may reflect signaling being relatively cheap: The lowest-rank person earned $\$ 5.25$ and the average truffle consumption was 2 in rank-private, so even the lowest-rank person could inexpensively engage in signaling competition.
} 
demanded by men is $477 \%$ higher in rank-public than rank-private. Individuals who scored high on a measure of cognitive reflection (Frederick, 2005), which is the propensity to engage in conscious deliberation when a situation requires it, also engage more in conspicuous consumption. We find no impact of risk aversion or competitive social preferences on conspicuous consumption. Publicly visible choice causes participants to buy chocolate truffles at higher prices than they would have otherwise. By comparing the demand curves in rank-private and rank-public, we can estimate both the rank-private consumer surplus and the average welfare loss from making consumption public. We find that the average welfare loss is as large as the consumer surplus when the price of chocolate is $\$ 0.40$, which is approximately the retail price. The negative effect of conspicuous consumption on welfare loss comes primarily from men, who account for most of the conspicuous consumption. For women, the loss is much smaller and insignificant.

The non-monotonic relationship between consumption and income means that public consumption does not convey a credible signal about status, which means that the welfare loss from conspicuous consumption is not compensated by signaling value of such consumption. To investigate whether participants derive utility from conspicuous consumption unrelated to signaling, we asked them to rate their mood at the end of the experiment. For men, we find no difference in self-reported mood between rank-public and rank-private. To the extent that our simple mood measure captures the non-consumption externalities of status signaling, it provides suggestive evidence that the net welfare effect of conspicuous consumption is negative for men. Women's moods are low in rank-private, so the net welfare effect of conspicuous consumption for them is likely positive. However, it is possible that our measure does not fully capture the nonconsumption externalities of status signaling. We discuss some possibilities in the conclusion. 
We describe the experimental design and procedures in Section 2. Our main results are presented in Section 3, along with analyses of how conspicuous consumption is related to the level of status, the characteristics of those who engage in conspicuous consumption, and the welfare effects of conspicuous consumption. We discuss connections to the literature and implications of our results in Section 4.

\section{Experimental Design and Procedures}

The experiment was conducted at Case Western Reserve University. We recruited participants from an email pool of undergraduate and graduate students. There were 12 sessions with 12 participants each, for a total of 144 participants. Participants were seated in an ordinary classroom. The experiment consisted of several parts and participants received instructions (available in Appendix A) at the beginning of each part.

In all sessions, participants completed a 30-minute cognitive test consisting of 20 multiplechoice questions. The questions were drawn from a Graduate Record Examination (GRE) test preparation book (Seltzer, 2009). There were 10 mathematical and 10 verbal questions. All were of moderate to high difficulty. Participants worked using pencil and paper and recorded their responses on bubble sheets. The sheets were scanned and scored after 30 minutes had elapsed. Each participant received one point for each correct response and lost one point for each incorrect answer. Unanswered questions carried no penalty. Participants were ranked according to the resulting score, and received a sheet indicating their score and rank among their fellow participants.

We employed the two-by-two design shown in Table 1. The first treatment manipulation varied the manner in which participants received income. There were 12 income levels between $\$ 5$ and $\$ 13.25$. In the rank treatments, income was allocated based on each participant's rank on 
the test. The participant who ranked first on the test got $\$ 13.25$, while the participant who ranked last got \$5. Participants were given a table showing how rank translated into income with their own rank and income circled. In the random treatments, income was allocated using a random draw without replacement. Participants privately drew a card from bag containing cards numbered 1 through 12. Each participant had a table showing how the random numbers translated into income, from $\$ 5$ for number 12 to $\$ 13.25$ for number 1 . As a result of this procedure, income and performance on the test are positively correlated in the rank treatments and uncorrelated in the random treatments.

Participants were then given an opportunity to spend some of their income on gourmet chocolate truffles. We chose gourmet chocolate truffles because 1) they are a rival and excludable consumption good; 2) they are desirable to participants; 3) they are packaged as small, discrete pieces; and 4) they are of high quality. We wanted a rival and excludable good rather than a public good, such as a donation to charity, because the benefit of consuming it is purely private. The motivations underlying demand for rival and excludable goods are less complex, which makes interpretation of behavior clearer.

Participants completed a table that listed nine potential truffle prices between $\$ 0.20$ and $\$ 0.60$. We asked each participant to indicate how many truffles they would like to purchase at each of nine potential prices and explained that the roll of a die would later determine the actual price. They could indicate any quantity between zero and a number exhausting their total income and would then purchase the indicated quantity corresponding to the actual price. Participants were told that the remaining cash would be paid to them at the end of the session. Calculators were provided for this portion. 
The second treatment manipulation varied how the participants would communicate the quantity of chocolate they purchased. Before participants completed the table of chocolate choices, we told them how they would receive their selection once the actual price was determined. In the private treatments, we explained that we would collect their selection tables and package the chocolate at the side of the classroom in brown paper bags labeled with their subject numbers. This would keep everyone's selections private. Bags would be distributed as participants came up to get their payments at the end of the experiment. Each participant would get a bag regardless of whether they purchased any chocolate. In the public treatments, participants were told that after the actual price was determined, each participant would come up to the whiteboard and write the quantity of chocolate they selected and the total cost along with their first name and subject number. We told them that this would speed up our packaging of the chocolate and computation of payments, which was true.

We collected several other types of data to help us understand what individual characteristics might mediate the effects of our treatments. Before the GRE test, we measured cognitive reflection. After participants completed their chocolate choice tables but before the actual price was determined, we collected measures of risk aversion, social preferences, and demographic characteristics. The risk aversion and social preferences measures were incentivized.

The three-question cognitive reflection test (CRT) was participants' first task in the session (Frederick, 2005). The CRT questions are simple math problems designed to have an intuitively appealing solution that is incorrect. The test measures an individual's ability to resist their intuition and arrive at the correct solution. For example, the first question is " $\mathrm{A}$ bat and a ball cost $\$ 1.10$ in total. The bat costs $\$ 1.00$ more than the ball. How much does the ball cost?" The appealing but incorrect answer is $\$ 0.10$. The correct answer is $\$ 0.05$. 
Participants made a series of 20 binary choices to measure risk aversion (similar to Holt and Laury, 2002). The choices involved a risk-free amount varying from $\$ 0.50$ to $\$ 10.00$ and a lottery offering a 50\% chance to get $\$ 10$ and a 50\% chance to get nothing (see Appendix A). One of the 20 choices was randomly selected to be paid out at the end of the experiment. We measure risk aversion using a dummy that identifies whether a participant was more risk averse than the median.

Next, participants made 12 binary choices to measure social preferences (similar to Charness and Rabin, 2002). The choices involved additional income for themselves and another participant with whom they were anonymously paired. Each choice offered the option of $\$ 3$ to both self and other or an unequal amount with total value between $\$ 3.50$ and $\$ 8.50$ (see Appendix A). One of the 12 choices was randomly selected to be paid out at the end of the experiment, and one of the paired participants was randomly selected to be the decision maker, while the other was selected as a receiver. We use these choices to distinguish participants who always maximize social welfare from those with competitive preferences. We define a measure of competitive social preferences as the share of choices in which a participant sacrificed social welfare to increase the amount by which their payment would be greater than the receiver.

Finally, at the end of the experiment, random draws were conducted to determine payouts for the risk aversion and social preferences choices as well as the price of chocolate. As the chocolate was being packaged at the end of the experiment, participants completed a demographic survey. On average participants earned $\$ 15.18$ and the experiment lasted for about 70 minutes. 


\section{Results}

In this section we present the main results. We start by describing participant characteristics and our main findings. We then examine how conspicuous consumption is related to status level and what types of participants are most likely to engage in conspicuous consumption. Finally, we analyze the welfare effects of conspicuous consumption.

\subsection{Participant Characteristics}

Table 2 shows the characteristics of our 144 participants. Over three-quarters of our participants are undergraduate students. They come from a wide range of majors and departments. Only $13 \%$ of participants study economics, finance, or another business-related field. On average, participants are 20 years old. Gender composition is balanced, with $48 \%$ female and $52 \%$ male students. Whites make up 58\%, Asians 25\%, and African-Americans $8 \%$. The average income in their family of origin is $\$ 141,000$. About $42 \%$ work in addition to studying, and of those who do, the average work week is 11.5 hours. Overall, our participant pull is representative of the student body of Case Western Reserve University.

\subsection{Main Findings}

Our main question of interest is whether participants engage in conspicuous consumption. If there is no conspicuous consumption, we should observe no difference in demand for chocolate across our treatments. If there is conspicuous consumption when income is linked to social status, we should observe greater demand in rank-public than rank-private. If conspicuous consumption is about signaling one's income level itself, we should observe greater demand in random-public than random-private. 
Figure 1 shows aggregate chocolate demand curves for each of the four treatments. The markers show the total quantity demanded at each potential price for the 36 participants in each treatment. Across all treatments, as standard microeconomic theory predicts, the quantity demanded falls as price increases. Demand for chocolate in the rank-public treatment is much higher than the other three treatments. The demand shift is so large that this curve has limited overlap with the others despite price varying by a factor of three. The curves tell us that making choices publicly visible increases demand when income is related to status but not when it is assigned randomly.

We show the average quantity demanded over all potential prices for the four treatments in Table 3. Mean quantity demanded is 1.94 in rank-private and 4.98 in rank-public, a large and statistically significant difference of $257 \%$. The total income available to spend on chocolate is the same in rank-public and rank-private, and its distribution in terms of test performance is also the same. This allows us to interpret the increased consumption as a causal effect of making consumption visible. By contrast, when income is assigned randomly rather than by test rank, mean quantity demanded is 1.74 in random-private and 1.75 in random-public. Again, the total income available to spend on chocolate is the same in random-public and random-private, and its distribution in terms of test performance is also the same. This tells us that visibility alone is not enough to induce an increase in consumption. Income must be correlated with status, here performance on the test, for public visibility to induce conspicuous consumption. In other words, the necessary conditions for conspicuous consumption are 1) income must be correlated with status and 2) consumption choices must be publicly visible to others.

We explore how quantiles of demand vary by treatment for different prices in Table 4. Panel A compares rank-private and rank-public. All quantiles of demand are higher in the rank- 
public treatment for every price level. A Wilcoxon rank-sum test at each price level shows the differences in distributions to be statistically significant. All but one of the p-values are less than 0.05 and most are less than 0.01. Panel B compares random-private and random-public. The Wilcoxon test shows no statistically significant difference in the distributions at any price other than $\$ 0.25$. Overall, the detailed analysis shows that differences found for means from Table 3 are reflected at all prices and parts of demand curves.

Treatments were randomly assigned to experimental sessions, so the expectation is for participants in each session to be the same on average in terms of their characteristics. It is nevertheless possible that participants in different sessions differ in ways important for demand. To check the robustness of our results, we conduct a regression analysis in which we examine whether controlling for observable characteristics affects our results.

Let $q_{i p}$ be the chocolate demanded by individual $i$ when the price is $p, X_{i}$ be a vector of characteristics for $i$, Public $i_{i}$ indicate whether consumption choice of $i$ is public, and Rank indicate whether $i$ 's income was assigned by test rank. Our specification is then

$$
q_{i p}=\alpha+\beta_{P} \text { Public }_{i}+\beta_{R} \text { Rank }_{i}+\beta_{P R}\left(\text { Public }_{i} \times \text { Rank }_{i}\right)+X_{i}^{\prime} \theta+\varepsilon_{i p} .
$$

When estimating this regression, we compute standard errors allowing for arbitrary correlation of $\varepsilon_{i p}$ within each individual. Our control vector includes the characteristics we elicited from our participants as shown in Table 2.

Table 5 reports the results of estimating equation (1) using OLS. Column 1 shows estimates without any controls. The constant shows average quantity demanded in random-private. Average quantity demanded in other treatments replicating the means from Table 2 may be obtained by adding the appropriate coefficients from the set Public, Rank, and Public $\times$ Rank. Notably, the differences in average quantity demanded computed from the regression are $3.04(\mathrm{p}<0.01)$ between 
rank-public and rank-private and $0.01(\mathrm{p}=0.99)$ between random-public and random-private. Column 2 adds in controls for participant characteristics. Demand is higher for those who have consumed chocolate in the recent past and lower for those who have eaten in the past five hours, which makes intuitive sense. Demand is also lower for African-Americans. However, addition of the controls does not measurably affect the differences between treatments. Conditional on controls, the differences in average quantity demanded are $3.39(\mathrm{p}<0.01)$ between rank-public and rank-private and $-0.72(\mathrm{p}=0.26)$ between random-public and random-private.

Result 1: Making consumption choices visible strongly increases demand when income is linked to status, but not when income is assigned randomly.

\subsection{Levels of Status and Conspicuous Consumption}

Chocolate demand is higher when consumption is public for participants whose income was assigned according to rank, suggesting that participants engage in conspicuous consumption by buying chocolate to signal their status. In this section, we examine whether conspicuous consumption varies by status level. If high consumption of visible goods serves as a signal of high status, we might expect the relationship between a person's level of status and the degree to which they engaged in conspicuous consumption to be positive. However, if individuals signal strategically, then it is also possible to obtain non-monotonic relationship between status and conspicuous consumption, especially if some participants choose to countersignal their status (Spence, 1973; Feltovich et al., 2002).

In our experiment, status is conferred by one's rank on the cognitive test. When income is assigned by rank, status and income are directly correlated. Previously, we established that conspicuous consumption takes place when income is assigned by rank. To uncover how 
conspicuous consumption is related to rank, we plot Engel curves for chocolate demand. The Engel curve shows how the share of income spent on chocolate varies with income. Figure 2 displays Engel curves for all four treatments of our experiment. On the vertical axis, participants are binned by six income levels. On the horizontal axis, the share of income spent on chocolate is averaged across all nine potential prices for each participant. All four curves appear non-monotonic, though we must be cautious in interpreting the shapes as there are only six observations behind each data point. As with total demand, the rank-private Engel curve stands out as distinct from the other treatments.

We focus on the difference between the rank-private and rank-public curves in Figure 3. The graph shows the mean effect of visibility on demand for six income/rank levels computed using regression. Confidence intervals for each difference are shown using dotted lines. Conspicuous consumption is clearly non-monotonic in status. Participants of moderately low and moderately high status are most affected. Those in the middle are less affected.

Result 2: Status level has a non-monotonic impact on conspicuous consumption, with participants of moderately high and moderately low status engaging in conspicuous consumption more than participants of middle status.

\subsection{Who Engaged in Conspicuous Consumption?}

In this section we explore to what extent conspicuous consumption is mediated by individual characteristics such as gender, risk aversion, competitive social preferences, and cognitive reflection. We collected information about these characteristics because we suspected that there could be similarities between conspicuous consumption and competitive behavior. In particular, in signaling through consumption it is important to consume more than others. A 
number of studies have documented that competitive behavior is linked to gender (Niederle and Vesterlund, 2007), risk preferences (Cason et al., 2010), and competitive social preferences (Dohmen and Falk, 2011). ${ }^{7}$ We also suspected that cognitive reflection (Frederick, 2005) could be important because our treatment manipulations require participants to be sensitive to a social setting they are in.

We investigate these mediating factors through a regression of the quantity of chocolate demanded at the price-individual level on a dummy variable Public $c_{i}$ for the public treatment, a dummy variable $M_{i}$ that categorizes the mediating factor, the interaction $P u b l i c_{i} \times M_{i}$, and a vector of additional controls $X_{i}$.

$$
q_{i p}=\alpha+\beta_{P} \text { Public }_{i}+\beta_{P M}\left(\text { Public }_{i} \times M_{i}\right)+\gamma M_{i}+X_{i}^{\prime} \theta+\varepsilon_{i p}
$$

The coefficient $\beta_{P}$ measures the effect of making choice public for those who have a zero value for the mediating factor dummy while $\beta_{P M}$ measures the differential effect of public choice on those who have a value of one for the dummy. We control flexibly for test rank by including a dummy variable for each of the 12 test ranks in the control vector $X_{i}$.

Table 6 reports the estimation results of specification (2). The unconditional effect on quantity demanded of making consumption public is 3.04 (column 1). The mediators have no statistically significant effects of their own on quantity demanded when added as controls, and the coefficients are much smaller than the effect of public choice, which remains unchanged (column 2). Adding the interaction of public with female gender shows that the effect of public choice comes entirely from men. The effect for men is $5.93(\mathrm{p}<0.01)$, while for women it is only 0.55 and is not statistically significantly different from zero (column 3). Similarly, visibility seems to primarily affect those individuals who have high CRT scores. The effect for high CRT individuals

\footnotetext{
${ }^{7}$ For a review of this literature see Dechenaux et al. (2015).
} 
is $5.29(\mathrm{p}<0.01)$, while it is only 0.61 and not significantly different from zero for low CRT scorers (column 4). Recall that these regressions control for cognitive test rank. CRT scores are, unsurprisingly, correlated with cognitive test scores (Spearman's $\rho=0.55$ ). The effect measured here is therefore for that aspect of CRT not correlated with the cognitive test (e.g., impulsivity of behavior). ${ }^{8}$ Participants with higher risk aversion are more affected by visibility, though the effect is not statistically significant (column 5). Having above-median competitive social preferences reduce the impact of public consumption (column 6). When we include all mediators in the regression, gender and cognitive reflection remain important mediators (column 7). The magnitudes are not much changed from the separate regressions. Interestingly, competitive social preferences are correlated with gender and CRT, which helps explain why the interaction of competitive social preferences with public consumption is attenuated in the full regression.

Given that gender and cognitive reflection are the most robust mediators, we now compute the effect of conspicuous consumption on the four CRT-gender groups. We use the following regression:

$$
\begin{array}{r}
q_{\text {ip }}=\alpha+\beta_{1} \text { Public }_{i}+\beta_{2}\left(\text { Public }_{i} \times \text { Female }_{i}\right)+\beta_{3}\left(\text { Public }_{i} \times C R T_{i}\right)+\beta_{4}\left(\text { Public }_{i} \times\right. \\
\text { Female } \left._{i} \times C R T_{i}\right)+\gamma_{1} \text { Female }_{i}+\gamma_{2} C R T_{i}+\gamma_{3}\left(\text { Female }_{i} \times C R T_{i}\right)+X_{i}^{\prime} \theta+\varepsilon_{i p} .
\end{array}
$$

In the regression Female $_{i}$ is a dummy variable for female gender and $C R T_{i}$ is a dummy for high CRT.

Table 7 shows the estimated coefficients of the interacted specification (3). We use these coefficients to compute the effect of making choices in public on the consumption decisions of each of the four subgroups, which we present in Figure 4. The figure clearly shows that public

\footnotetext{
${ }^{8}$ We would expect the conditional CRT effect to be driven by impulsivity because, unlike with the CRT, inducing intuitive but incorrect response is not the only goal in the design of questions on the cognitive test.
} 
consumption has an effect on all male participants, though the effect is greater on high CRT males than low CRT males. Public consumption has no significant effect on females. The point estimate of the effect is greater for high CRT females than low CRT females, though neither are statistically different from zero.

Result 3: Making consumption choices visible has a large effect on men, particularly those who exhibit high levels of cognitive reflection. It has no significant effect on women.

\subsection{Welfare Effects of Conspicuous Consumption}

In this section we examine implications of conspicuous consumption for economic welfare. Figure 1 shows that the demand for chocolate is much higher in the rank-public treatment than in the rank-private treatment. This means that at any given price, when consumption is publicly visible participants choose to buy significantly more chocolate than when such consumption is private. Figure 1 allows us to see what equilibrium prices would have resulted if we had had a limited quantity of chocolate and prices were determined over all participants. For example, if we had 100 chocolates to sell, the price would have been $\$ 0.29$ in rank-private and $\$ 0.51$ in rankpublic, a difference of $76 \%$. The share of income spent on chocolate would have been $9 \%$ and $15 \%$, respectively. ${ }^{9}$

In the analysis to follow, we distinguish between two types of welfare effects. One type results from the excess purchases of chocolate. This is what economists usually mean by welfare. In addition, we must recognize that the experience of revealing one's consumption to others may be inherently pleasant or unpleasant. We use the terms decision welfare and experience welfare to distinguish between the two (see Kahneman et al., 1999).

\footnotetext{
${ }^{9}$ The total income available to spend on chocolate across all participants in each treatment was $\$ 328.50$.
} 
If we take demand in rank-private as representative of participants' underlying preferences for chocolate consumption, the excess consumption of chocolate when choices are public creates a loss of decision welfare. We can compute both consumer surplus in rank-private and the welfare loss from the data. Figure 5 shows the basic idea of our approach. First, we fix a market price of chocolate. We use the participants' data on chocolate demand to calculate the equilibrium quantity demanded in rank-private (demand without status signaling) and in rank-public (demand with status signaling). The area between the market price and the rank-private demand curve is the consumer surplus in the rank-private treatment. The area between the equilibrium quantity in the rank-public treatment, given by the intersection of the market price and the rank-public demand curve, the rank-private demand curve, and the market price is the welfare loss. The welfare loss represents the excess amount paid for the extra units of chocolate purchased in rank-public over what would have been paid for them had they actually been purchased in rank-private.

We measured demand in rank-public and rank-private at $\$ 0.05$ price intervals between $\$ 0.20$ and $\$ 0.60$. To compute the consumer surplus and the welfare loss, we must use this data to approximate a continuous demand curve. The consumer surplus calculation for a fixed market price requires an approximation of the rank-private demand curve for all prices for which demand would be positive. The welfare loss calculation for a fixed market price requires that the rankprivate demand curve be defined for the equilibrium rank-public quantity at that price. We approximate a continuous curve by fitting a fractional polynomial regression of quantity on price to the data in each treatment. A fractional polynomial regression allows for a more flexible range of curve shapes than a standard polynomial by including logarithms, negative powers, and noninteger powers of the independent variable (Royston and Altman, 1994). We use the subset of 
powers from the set $\left\{x^{-2}, x^{-1}, x^{-1 / 2}, \ln (x), x^{1 / 2}, x^{1}, x^{2}, x^{3}\right\}$ that maximizes the likelihood of the model to construct the curves.

We show the mean demand data and fitted values from the fractional polynomial models in Figure 6. Circles and diamonds represent, respectively, the mean quantity demanded for rankprivate and rank-public at each elicited price. The solid lines show the fitted curves. The curve for rank-private shows the out-of-sample extrapolations needed to calculate consumer surplus and the welfare loss for market prices between $\$ 0.20$ and $\$ 0.60$. We do not need to make extrapolations for rank-public. The rank-private fit uses two terms and the rank-public fit uses four terms. As Figure 6 shows, the fitted curves match the data quite closely. The $R^{2}$ for both fractional polynomial fits exceed 0.99 .

Recall that men are much more affected by communicating their consumption choices in public than women. We show demand data and fitted values separately for men and women in Figure 7. Note in particular the demand curves for men shown in Panel A. There is almost no overlap in elicited mean demand between the rank-private and rank-public treatments: participants purchase as much for $\$ 0.60$ per piece in rank-public as they do for $\$ 0.20$ per piece in rank-private. The shallowing of the rank-private fitted curve to the right of the elicited data depends a lot on the $\$ 0.20$ data point, and could in reality be steeper than our estimates.

We present our welfare computations in Table 8 . We begin with consumer surplus in the rank-private treatment for all participants (Panel A). For five fixed prices between $\$ 0.20$ and $\$ 0.60$, we calculate the area between the fitted demand curve, the price, and the zero-quantity line using a rectangular Riemann approximation with a price delta of $\$ 0.001$. Mean consumer surplus ranges from $\$ 0.01$ for a chocolate price of $\$ 0.60$ (at which mean demand is only 0.4 pieces) to $\$ 0.76$ for a chocolate price of $\$ 0.20$. The consumer surplus calculations are not very sensitive to 
assumptions because the fractional polynomial fits the data closely and relatively little out-ofsample extrapolation is used.

We also use a rectangular Riemann approximation to calculate the welfare loss of making consumption choices public. These rectangles lie between the rank-private demand curve and a vertical line descending from the intersection of the fixed price and the rank-public demand curve to the rank-private demand curve as shown in Figure 5. The mean welfare loss associated with public consumption choice is also shown in Table 8. The estimates for all participants range from $\$ 0.21$ to $\$ 0.49$ depending on which price we fix. Note that the $\$ 0.20$ and $\$ 0.30$ estimates rely on extrapolation of the rank-private demand curve. The estimated welfare losses are 0.7 to 25 times as large as consumer surplus. One implication of this is that, except at the subsidized prices of less than $\$ 0.40$, participants in the rank-public treatment would have been better off in decision welfare terms if we had never offered them the chance to buy chocolate. We can conclude that conspicuous consumption had a negative effect on decision welfare.

Next, we break down the consumer surplus and welfare loss calculations by gender. The estimates for men are shown in Table 8, Panel B. Men are not very price-sensitive in rank-private, so their consumer surplus is lower than average. It ranges from $\$ 0.01$ to $\$ 0.57$. As might be expected from the large effects of public choice on men's demand, the welfare losses for men are quite large, ranging from $\$ 0.52$ to $\$ 1.00$. Given the extrapolation used to calculate these figures, they should be taken as lower bounds. For women, consumer surplus is somewhat greater, ranging from zero to $\$ 0.94$ depending on price. The welfare losses from conspicuous consumption are of course lower, between $\$ 0.01$ and $\$ 0.13$, since women are not effected much by making consumption choice public. 
We measured experienced welfare by asking participants to rate their overall mood after the chocolate distribution was completed. They selected an item from a seven-point scale ranging from "very bad" to "very good". Experienced welfare is more difficult to measure than decision welfare because there is no single dimension like money into which behavioral data can be easily transformed. It is important to note that, for this reason, our measure does not capture all of the aspects or dimensions of experience that might bear on an understanding of welfare.

We asked participants about their mood after a number of sources of uncertainty had been resolved, in particular the actual price of chocolate and payouts for the risk aversion and social preferences measures. ${ }^{10}$ Participants had also turned in the sheets with their chocolate choices (in private treatments) or written their chocolate choices on the white board (in public treatments). Since along with the treatments, the actual price of chocolate, as well as the risk aversion and social preferences decisions selected for payout varied at the session level, we want to control for them when looking at how mood varies by treatments. It turns out that mood is positively correlated with take-home payouts and, perhaps counterintuitively, the realized price of chocolate (see regressions reported in Table B1 in Appendix B). In the analysis of how participant mood varies by treatment, we control for the actual price of chocolate, and payouts from risk aversion and social preferences elicitation.

We show the regression-adjusted mean mood of participants by treatment in Table $9 .{ }^{11}$ There is no sizable or statistically significant difference in mood between participants in randomprivate and random-public (Panel A). Recall there was also no difference in demand. The average

\footnotetext{
${ }^{10}$ This was done for two reasons. First, we tried to keep each session under 90 minutes and, given that our experiment was hand run, we were able to substantially shorten each session by having participants answer the survey questionnaire while their payoffs were calculated. Second, for a more meaningful measure of the experienced welfare it was important for participants to experience the actual process of status signaling through purchasing chocolate in the public treatments.

11 The unadjusted mean mood looks very similar and is shown in Table B2 in Appendix B.
} 
mood for both of these groups is just over 5, which corresponds to the response "a little bit good." Mood does differ between the treatments in which income is assigned by rank. In rank-private, the average mood is lower at 4.58 . But the average mood in rank-public is 5.14, similar to the random treatments. The difference of 0.56 points is statistically significant at $8 \%$. The effect of making consumption public has a positive effect on experienced welfare. It is also worth noting that when consumption is private, assigning income by rank rather than at random has a negative effect on overall mood.

We break down participant mood by gender in Panels B and C. Recall that male demand was most strongly affected by public choice. Interestingly, while the mean experienced welfare for men of 4.94 in rank-private is lower than 5.28 in rank-public, the difference is only -0.34 and is not statistically significant. The increase in experienced welfare due to public choice comes entirely through women. For women, mean experienced welfare in rank-private treatment of 3.56 was 1.73 points lower than the 5.29 in the rank public treatment. Even though public consumption scarcely changed women's choices, it did make them feel better. Note that experienced welfare in the random-private and random-public treatments averaged 4.8, which is much closer to rankpublic than rank-private. It might be more correct to say that when income was assigned by rank, private consumption made women unhappy to a greater extent than public consumption made them happy.

In summary, the experiment suggests that pubic consumption causes a loss of decision welfare by inducing more consumption of chocolate. This loss falls primarily on men, who accounted for most of the conspicuous consumption. The loss exceeds the consumer surplus of chocolate consumption by a wide margin, so that rank-public men were worse off in terms of decision welfare than if they had not been offered a chance to buy chocolate. Moreover, for men, 
we find no differences in self-reported moods between rank-public and rank-private, suggesting that the net welfare effect of conspicuous consumption is negative for men. For women, we find that the decision welfare loss is much smaller and insignificant. Also, for women, we find that conspicuous choice elevated their mood, suggesting an increase in experienced welfare, which probably results in positive net welfare effect of conspicuous consumption.

Result 4: Conspicuous consumption has a large negative effect on the decision welfare of men, who accounted for most of the conspicuous consumption. Conspicuous choice elevated the mood of female participants, but not of males, likely offsetting their small loss in decision welfare. The net welfare effect of conspicuous consumption is therefore negative for men and positive for women.

\section{Discussion and Conclusion}

Standard economic theory suggests that the utility people derive from the consumption of goods and services drives demand. Veblen proposed that, in addition to consumption utility, demand for publicly visible goods is also driven by the social signals they send about those who purchase them.

We use a controlled experiment to examine whether adding the element of visibility to the purchase of a good induces conspicuous consumption. Our experiment provides clear evidence that this happens. Although we are not the first to examine social status motivations using an experiment, our use of a physical good to measure of conspicuous consumption eliminates confounds present in previous studies. To the best of our knowledge, the only experimental studies attempting to find evidence of conspicuous consumption use contributions to charities and social dilemmas. For example, many laboratory and field experiments have found that recognizing 
donors by revealing their identities increases donations to charities and contributions to public good (Andreoni and Petrie, 2004; Soetevent, 2005; Ariely et al., 2009; Karlan and McConnell, 2014; Samek and Sheremeta, 2014). One may be tempted to conclude that this change of behavior is evidence of conspicuous consumption. However, it is not clear whether such change of behavior is due to social status (Glazer and Konrad, 1996; Hopkins and Kornienko, 2004), or due to other factors, such as a desire to be seen as generous (Ariely et al., 2009; Benabou and Tirole, 2006; Andreoni et al., 2009) or to avoid being seen as stingy (Bracha and Vesterlund, 2013; Samek and Sheremeta, 2014), or perhaps a purely altruistic desire to set an example for others to follow (Karlan and McConnell, 2014). The nice feature of our experimental design is that, instead of giving to a charity or another participant, our participants buy chocolate. Since buying chocolate provides only private benefit to the person who purchased it, we are able to study conspicuous consumption without confounding factors of generosity and altruism, which are present in other studies. Further, since participants did not know the consumption decisions of others, our experiment isolates the effect of conspicuous consumption from social learning (Grinblatt et al., 2008).

We manipulated not only the visibility of the consumption good but also the link between status and income. In human societies, income and status tend to be naturally related to one another. We show that the linkage of income to status is critical for producing the conspicuous consumption response to the visibility of one's choices to others. This rules out the hypothesis that conspicuous consumption is about signaling one's income level itself. The necessary conditions for conspicuous consumption are thus that 1) a good be visible to others and that 2) income be an indicator of one's status. 
Although our data provide support for a hypothesis that status is a significant factor motivating consumption of visible goods, the relationship between status level and conspicuous consumption is non-monotonic. Specifically, we find that participants of moderately high and moderately low status engage in conspicuous consumption more than participants of middle status. This pattern makes it difficult to infer someone's status from their chocolate purchases. However, such non-monotonicities are possible in signaling games when players counter-signal (Spence, 1973; Feltovich et al., 2002). ${ }^{12}$

In addition to finding direct evidence for conspicuous consumption, we also investigated the characteristics that mediate the effect. We found that men are significantly more likely to engage in conspicuous consumption than women. This finding contributes to an extensive literature on gender differences in behavior (Croson and Gneezy, 2009). A possible explanation why men engage in conspicuous consumption more than women is that men are more competitive (Niederle and Vesterlund, 2007). As such, when seen by others, men are more likely to express their competitiveness through generosity (Pan and Houser, 2011), or conspicuous consumption in our case. ${ }^{13}$ Alternatively, women may not care about the particular status attribute studied in our experiment - rank on a cognitive test - as much as men.

We also found that participants who exhibit high levels of cognitive reflection were more likely to engage in conspicuous consumption. We suspect that participants with high scorers on

\footnotetext{
${ }^{12}$ Another explanation, consistent with the signaling story, is that the low status participants try to avoid being recognized as the lowest performers on the test and thus purchase more chocolate. Yet another explanation is that people who performed poorly on the test might use consumption of chocolate to comfort themselves (although we find no support for this as low status people do not consume much chocolate in other conditions).

${ }^{13}$ Another explanation is that women may be discouraged from public consumption of chocolate, since purchasing a rich and highly caloric treat in public may have more negative connotations for women than men. Indeed, when income is allocated randomly, women consume less chocolate in the public condition than when consumption is private (see Table B3 in Appendix B).
} 
cognitive reflection test are better at comprehending the experiment and thus are more sensitive to treatment manipulations.

Finally, we provided estimates of the impact of conspicuous consumption on economic welfare. Status-seeking behavior may have significant negative effect on economic outcomes by leading to more aggressive sabotage in work places (Charness et al., 2013) and overly competitive behavior in contests (Sheremeta, 2015). ${ }^{14}$ Our study points a more fundamental negative impact of conspicuous consumption. When people engage in conspicuous consumption, they purchase more of a good than they would if consumption was private. This leads to a welfare loss for participants in the experiment 0.7 to 25 times as large as the baseline surplus, depending on prices. The loss for men, who were most affected by choosing publicly, was 1.7 to 52 times as large as the baseline surplus. These losses cannot be offset by non-consumption benefits of status signaling because, in the equilibrium that emerged in our experiment, status cannot be easily inferred from consumption patterns. Further, we find that the mood of men in our study was no different under publicly visible or private choice. ${ }^{15}$

Our findings have practical implications. The fact that we find people engaging in conspicuous consumption even though there is a little signaling value of such consumption speaks to the ongoing debate on whether to tax visible goods used for status signaling (Frank, 1999, 2008). Although such a policy could be warranted, our results contain a puzzle that we think ought to be resolved before making such a suggestion. Our participants engaged in conspicuous consumption even though there were no benefits to offset the decision welfare loss. Why did they do so? One

\footnotetext{
${ }^{14}$ Of course, in some environments status-seeking behavior may be beneficial to economy. For example, status and social recognition may be used to enhance worker performance (Kosfeld and Neckermann, 2011) or to encourage donations to charities (Karlan and McConnell, 2014; Samek and Sheremeta, 2014, 2015).

${ }^{15}$ In a market setting, conspicuous consumption of goods for which public visibility is an integral property will tend to raise prices. Depending on the shape of the demand curve, this may amplify or mute the decision welfare effect, though we expect it will be negative.
} 
possibility is that they incorrectly expected there to be signaling in equilibrium. If this was the case, we would expect conspicuous consumption to diminish in repeated trials. It is also possible that signaling is not the motivation for conspicuous consumption. Sending a signal in our experiment was fairly cheap, so participants could engage in counter-signaling. However, given a large difference in income between the highest ranked and the lowest ranked participants, this is unlikely to be the case. ${ }^{16}$ It is also possible that there are other non-consumption, non-signaling benefits to conspicuous consumption that we did not capture in our mood measure. ${ }^{17}$ We leave these questions for future research.

\footnotetext{
${ }^{16}$ In our experiment the highest ranked individuals made almost three times more than the lowest ranked individuals. So, the highest ranked individuals could have easily out-signaled the lowest ranked individuals and still earn more cash.

${ }^{17}$ Sivanathan and Pettit (2010) argue that individuals increase their demand for status goods when they receive negative information about themselves. They terms such information a self-threat. The response to such a threat is to engage in conspicuous consumption in order to restore or defend self-integrity. We can view those participants who ranked in the bottom third on the quiz as having received negative information about themselves. Table B4 in Appendix B reports estimation of two regressions for participants in the rank-private and rank-public treatments. The dependent variable in the first regression is the income share spent on consumption and in the second regression the dependent variable is mood. The independent variables are the dummies indicating treatment, female, having a test rank $>8$, as well as the interactions. The estimation results show that participants who receive negative information about themselves (i.e., test rank > 8) spend higher share of income on chocolate. Also, we find that there is no effect on participant mood for this subgroup. These findings are consistent with an interpretation that low-rank participants have lower mood if they fail to engage in extra chocolate consumption in the rank-public treatment (although the evidence is not causal).
} 


\section{References}

Andreoni, J., \& Bernheim, B.D. (2009). Social image and the 50-50 norm: A theoretical and experimental analysis of audience effects. Econometrica, 77, 1607-1636.

Andreoni, J., \& Petrie, R. (2004). Public goods experiments without confidentiality: a glimpse into fund-raising. Journal of Public Economics, 88, 1605-1623.

Ariely, D., Bracha, A., \& Meier, S. (2009). Doing good or doing well? Image motivation and monetary incentives in behaving prosocially. American Economic Review, 544-555.

Bagwell, L.S., \& Bernheim, B.D. (1996). Veblen effects in a theory of conspicuous consumption. American Economic Review, 86, 349-373.

Benabou, R., \& Tirole, J. (2006). Incentives and prosocial behavior. American Economic Review, 99, 544-555.

Bracha, A., \& Vesterlund, L. (2013). How low can you go? Charity reporting when donations signal income and generosity. Working Paper.

Cason, T.N., Masters, W.A., \& Sheremeta, R.M. (2010). Entry into winner-take-all and proportional-prize contests: An experimental study. Journal of Public Economics, 94, 604611.

Charles, K.K., Hurst, E., \& Roussanov, N. (2009). Conspicuous consumption and race. Quarterly Journal of Economics, 124, 425-67.

Charness, G., \& Rabin, M. (2002). Understanding social preferences with simple tests. Quarterly Journal of Economics, 117, 817-869.

Charness, G., Masclet, D., \& Villeval, M.C. (2013). The dark side of competition for status. Management Science, 60, 38-55.

Croson, R., \& Gneezy, U. (2009). Gender differences in preferences. Journal of Economic Literature, 47, 448-474.

Dechenaux, E., Kovenock, D., \& Sheremeta, R.M. (2015). A survey of experimental research on contests, all-pay auctions and tournaments. Experimental Economics, 18, 609-669.

Dohmen, T. \& Falk, A. (2011). Performance pay and multidimensional sorting: Productivity, preferences, and gender. American Economic Review, 101, 556-90.

Feltovich, N., Harbaugh, R., \& To, T. (2002), Too cool for school? Signaling and countersignalling. RAND Journal of Economics, 33, 630-649.

Frank, R.H. (1999). Luxury fever: Money and happiness in an era of excess. New York: The Free Press.

Frank, R.H. (2008). Should public policy respond to positional externalities? Journal of Public Economics, 92, 1777-1786.

Frederick, S. (2005). Cognitive reflection and decision making. Journal of Economic Perspectives, $19,25-42$.

Glazer, A., \& Konrad, K. A. (1996). A signaling explanation for charity. American Economic Review, 86, 1019-1028.

Grinblatt, M., Keloharju, M., \& Ikäheimo, S. (2008). Social influence and consumption: Evidence from the automobile purchases of neighbors. Review of Economics and Statistics, 90, 735753.

Heffetz, O. (2011). A test of conspicuous consumption: Visibility and income elasticities. Review of Economics and Statistics, 93, 1101-1117.

Holt, C.A., \& Laury, S.K. (2002). Risk aversion and incentive effects. American Economic Review, 92, 1644-1655. 
Hopkins, E., \& Kornienko, T. (2004). Running to keep in the same place: Consumer choice as a game of status. American Economic Review, 94, 1085-1107.

Kahneman, D., Diener, E., \& Schwarz, N. (1999). Well-being: The foundations of hedonic psychology. New York: Russell Sage Found.

Karlan, D., \& McConnell, M. A. (2014). Hey look at me: The effect of giving circles on giving. Journal of Economic Behavior and Organization, 106, 402-412.

Kosfeld, M., \& Neckermann, S. (2011). Getting more work for nothing? Symbolic awards and worker performance. American Economic Journal: Microeconomics, 3, 86-99.

Kuhn, P., Kooreman, P., Soetevent, A., \& Kapteyn, A. (2011). The effects of lottery prizes on winners and their neighbors: Evidence from the Dutch postcode lottery. American Economic Review, 101, 2226-2247.

Leibenstein, H. (1950). Bandwagon, snob, and Veblen effects in the theory of consumers' demand. Quarterly Journal of Economics, 64, 183-207.

Niederle, M. \& Vesterlund, L. (2007). Do women shy away from competition? Do men compete too much? Quarterly Journal of Economics, 122, 1067-1101.

Pan, X.S., \& Houser, D. (2011). Competition for trophies triggers male generosity. PloS One, 6(4), e18050.

Ravina, E. (2007). Habit formation and keeping up with the Joneses: Evidence from micro data. Working paper.

Royston, P., \& Altman, D.G. (1994). Regression using fractional polynomials of continuous covariates: Parsimonious parametric modelling. Applied Statistics, 43, 429-467.

Samek, A.S., \& Sheremeta, R.M. (2014). Recognizing contributors: An experiment on public goods. Experimental Economics, 17, 673-690.

Samek, A.S., \& Sheremeta, R.M. (2015). Selective recognition: How to recognize donors to increase charitable giving. Working Paper.

Seltzer, N. (2009). 1,014 GRE practice questions. Princeton Review.

Sheremeta, R.M. (2015). Impulsive behavior in competition: Testing theories of overbidding in rent-seeking contests. Working Paper.

Sivanathan N., \& Pettit, N.C. (2010). Protecting the self through consumption: Status goods as affirmational commodities. Journal of Experimental Social Psychology, 46, 564-570.

Soetevent, A. (2005). Anonymity in giving in a natural context - a field experiment in 30 churches. Journal of Public Economics, 89, 2301-2323.

Spence, M. (1973). Job market signaling. Quarterly Journal of Economics, 87, 355-374.

Veblen, T. (2009 [1899]). The theory of the leisure class: An economic study in the evolution of institutions. New York: Macmillan 
Figure 1: Aggregate Demand Curves by Treatment

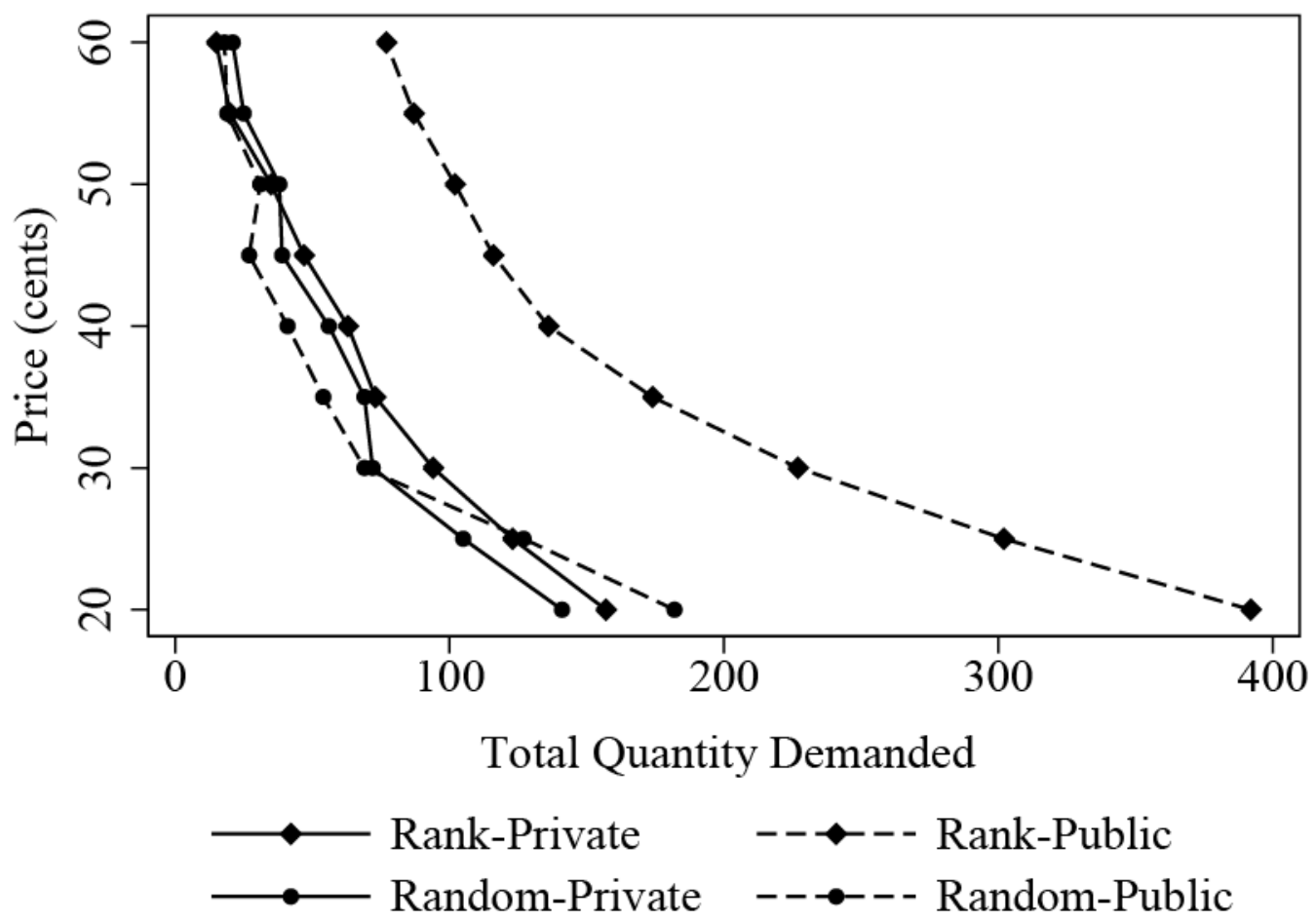

Notes: Lines plot total quantity demanded for each potential price of chocolate in each treatment. 
Figure 2: Engel Curves by Treatment

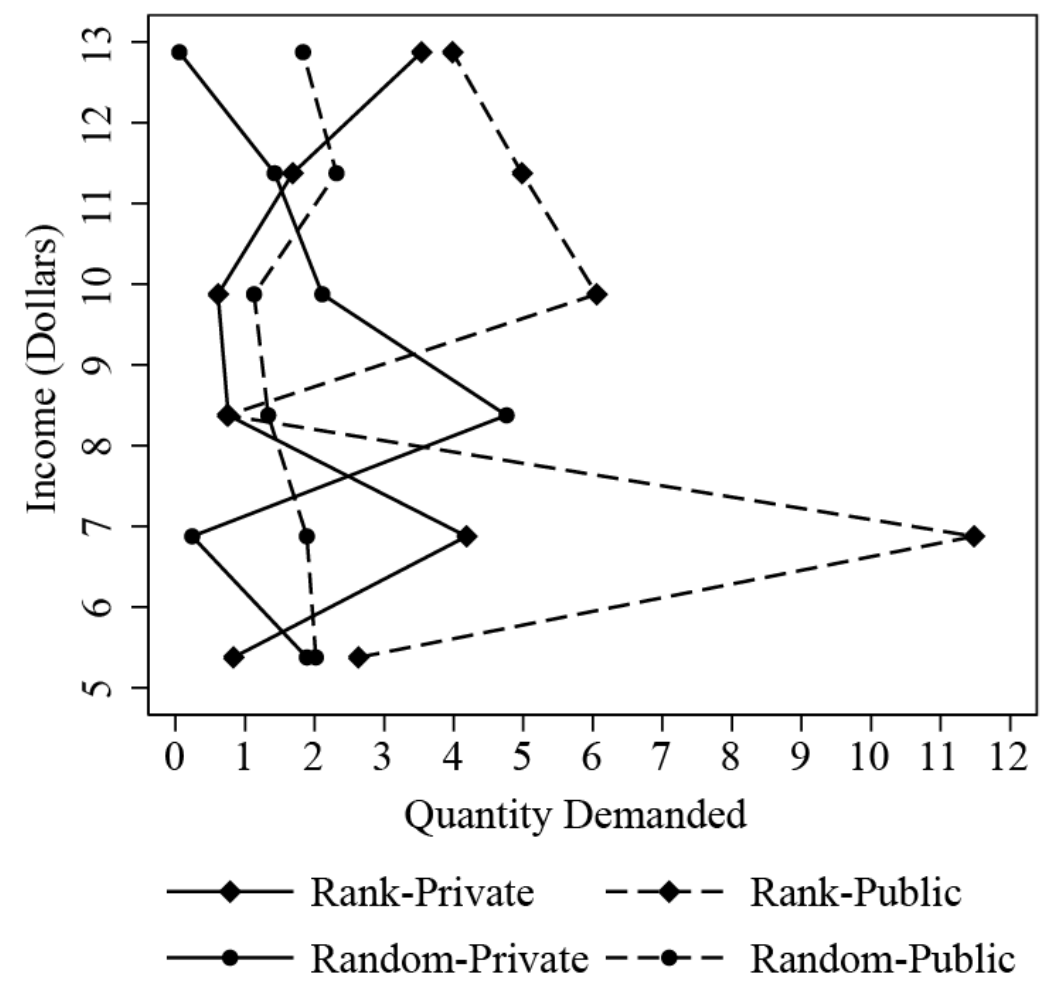

Notes: Lines plot the quantity demanded averaged across all nine potential prices for participants in each treatment. Participants are binned by six income levels, which correspond to test ranks 1 and 2 , 3 and 4 , etc. 
Figure 3: Conspicuous Consumption by Income/Status Level

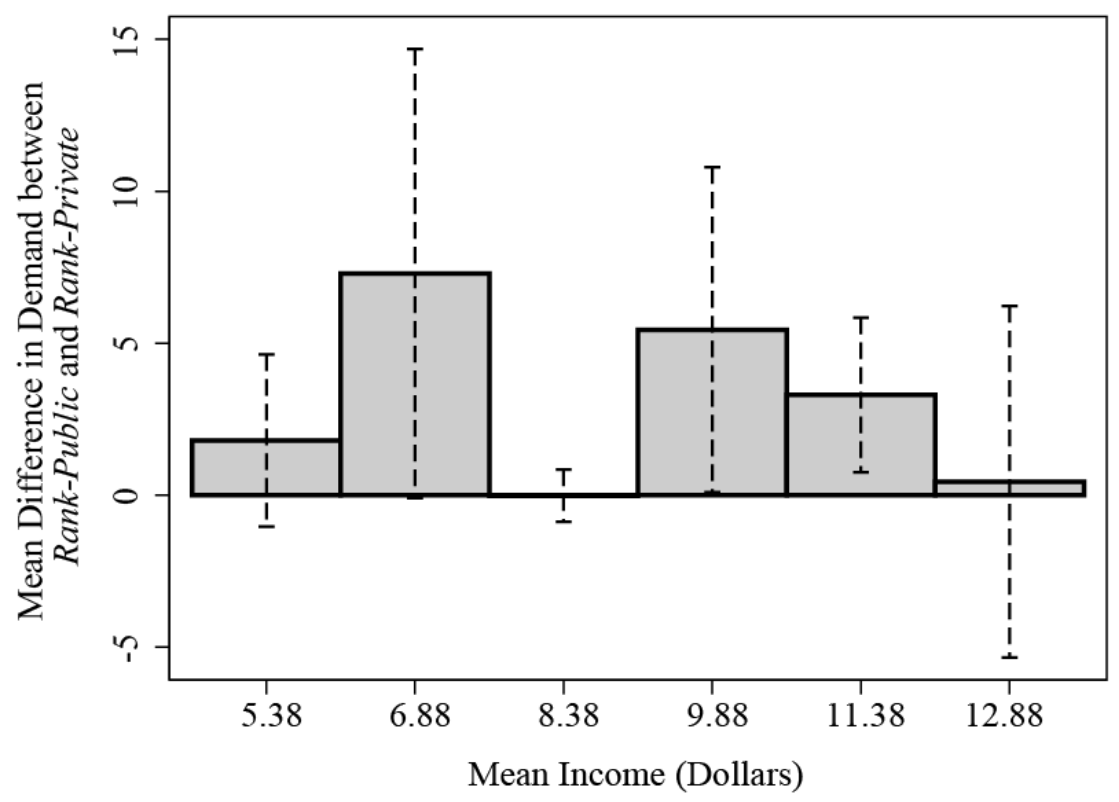

Notes: Graph shows differences in mean income share spent on chocolate between the rank-private and rank-public treatments for six income/status bins. Differences and confidence intervals computed from a regression of mean income share on bin dummies, a public choice dummy, and their interactions. Confidence intervals allow for heteroskedasticity. 
Figure 4: Conspicuous Consumption Effects by Subgroup

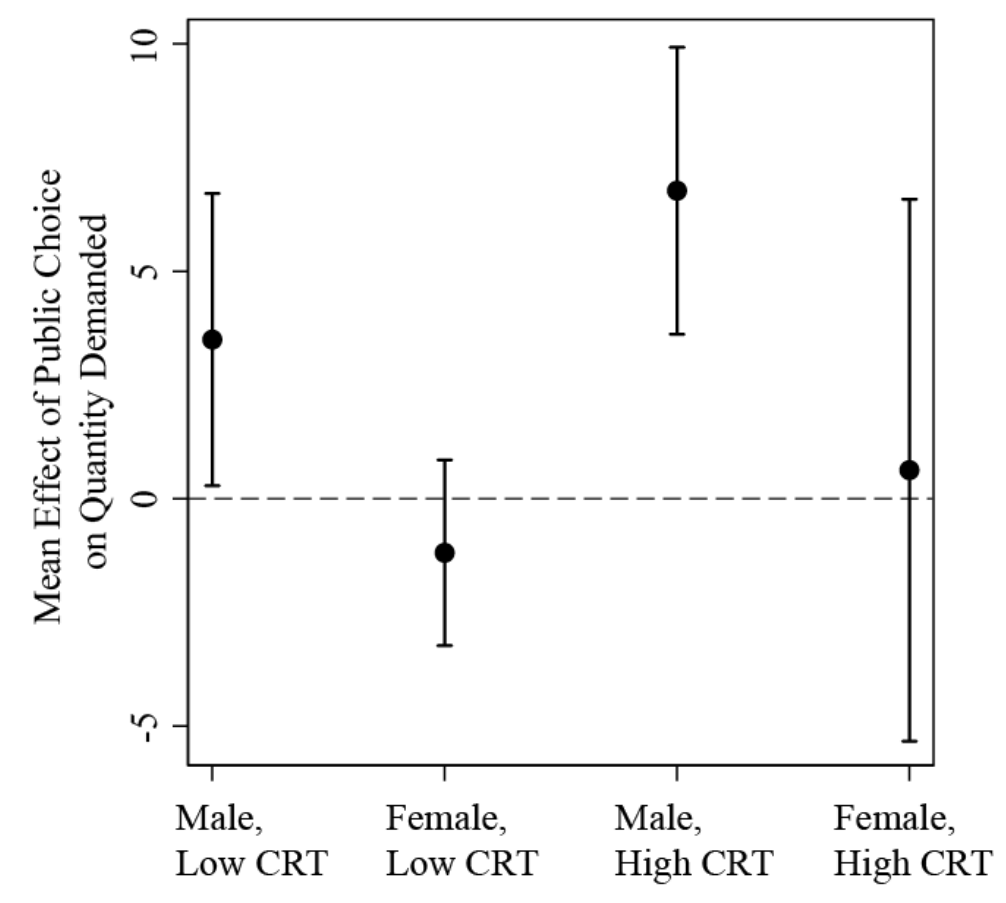

Notes: Graph shows estimated difference in mean quantity demanded for each subgroup between rank-private and rank-public. Estimates computed from regression that interacts a public treatment dummy with dummies for female gender and high CRT and their interaction. Bars show 95\% confidence intervals. 
Figure 5: Welfare Loss from Conspicuous Consumption

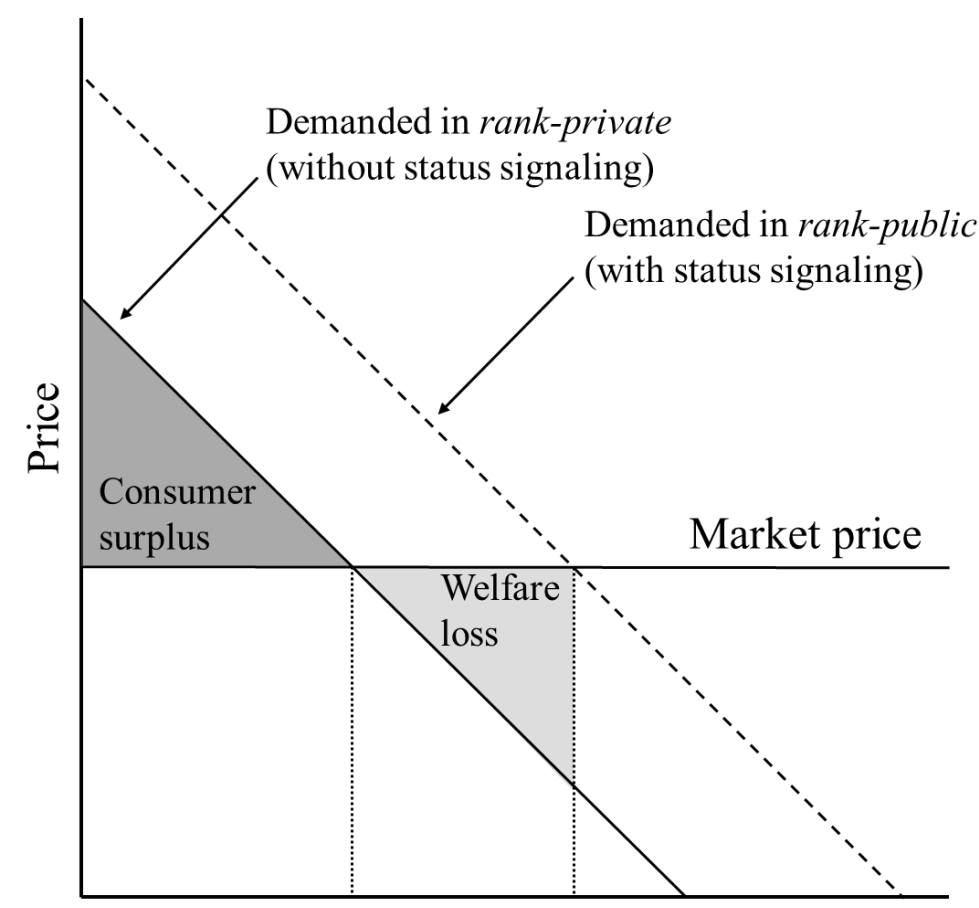

Quantity Demanded 
Figure 6: Fitted Demand Curves for Rank-Public and Rank-Private

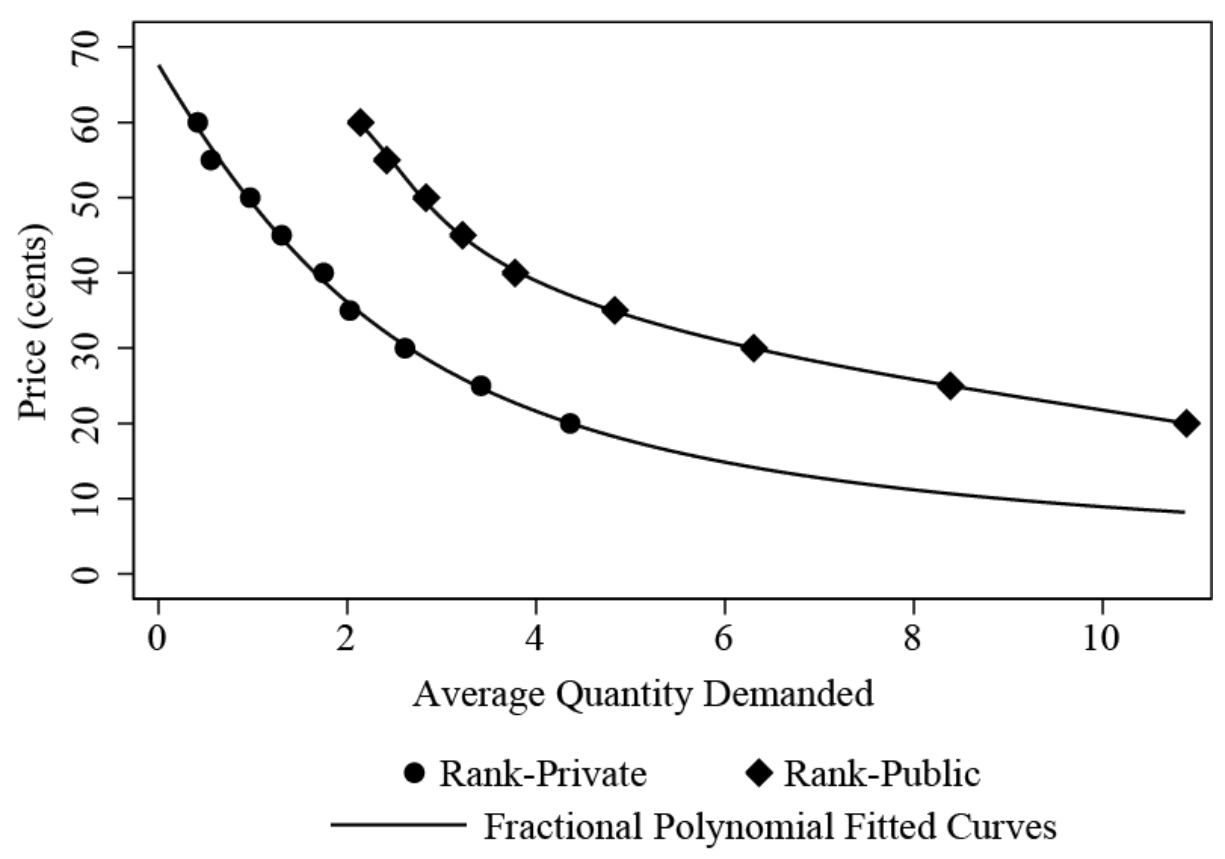

Notes: Lines show fitted values from fractional polynomial regressions as described in Section 3.5. 
Figure 7: Fitted Demand Curves for Rank-Public and Rank-Private By Gender

Panel A: Men
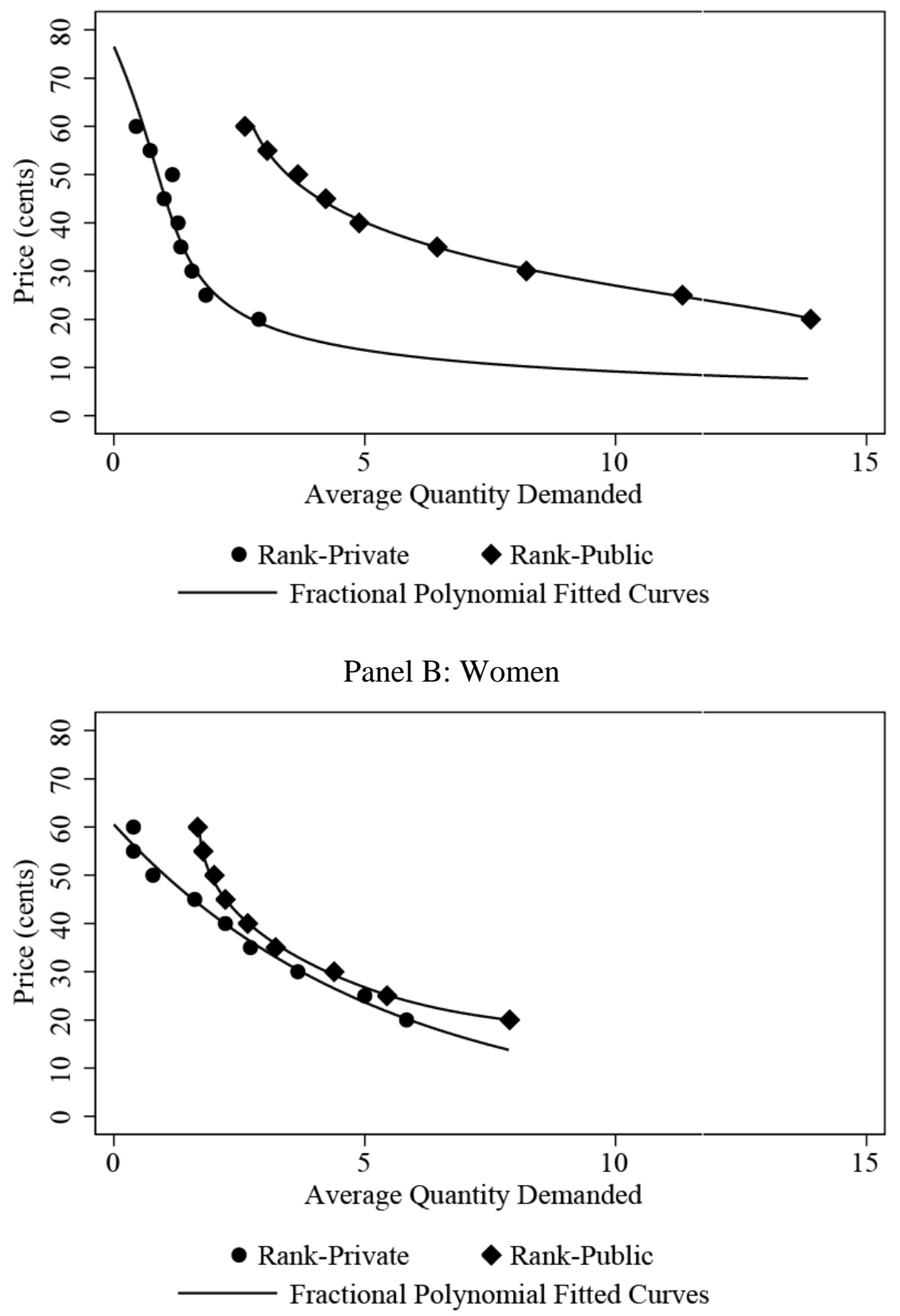

Notes: Lines show fitted values from fractional polynomial regressions as described in Section 3.5. 
Table 1: Treatments

\begin{tabular}{c|c|c}
\hline & \multicolumn{2}{c}{ Chocolate choice } \\
\hline Income allocation & Private & Public \\
\hline \multirow{2}{*}{ Rank } & 3 sessions, & 3 sessions, \\
& 36 participants & 36 participants \\
\hline \multirow{2}{*}{ Random } & $\begin{array}{c}\text { 3 sessions, } \\
\text { 36 participants }\end{array}$ & $\begin{array}{c}3 \text { sessions, } \\
\text { 36articipants }\end{array}$ \\
\hline
\end{tabular}

Table 2: Participant Characteristics

\begin{tabular}{l|llll}
\hline & Mean & SD & Min & Max \\
\hline Female & 0.48 & & & \\
Age & 19.96 & 1.88 & 18 & 23 \\
White & 0.58 & & & \\
Asian & 0.25 & & & \\
African-American & 0.08 & & & \\
Undergraduate & 0.78 & & & \\
Study Economics/Business & 0.13 & & & \\
Family Income & $141 \mathrm{~K}$ & $116 \mathrm{~K}$ & $20 \mathrm{~K}$ & $400 \mathrm{~K}$ \\
Employed & 0.42 & & & \\
Average Hours if Employed & 11.53 & 10.10 & 0 & 40 \\
CRT Score & 1.50 & 1.18 & 0 & 3 \\
GRE Test Score & 6.80 & 5.19 & -7 & 14 \\
Risk Aversion & 0.54 & & & \\
Competitive Social Preferences & 0.14 & & & \\
Had Chocolate Today/Yesterday & 0.49 & & & \\
Last Ate < 5 Hours Ago & 0.60 & & & \\
\hline
\end{tabular}


Table 3: Mean Quantity Demanded by Treatment

\begin{tabular}{lccc}
\hline & Random & Rank & $\begin{array}{c}H_{0}: \text { Random } \\
=\text { Rank }\end{array}$ \\
\hline Private & 1.74 & 1.94 & $\mathrm{p}=0.82$ \\
Public & 1.75 & 4.98 & $\mathrm{p}<0.01$ \\
\hline $\mathrm{H}_{0}:$ Public = Private & $\mathrm{p}=0.99$ & $\mathrm{p}<0.01$ & \\
\hline
\end{tabular}

Notes: Means for each treatment are computed by averaging over all potential prices. The tests of the null hypotheses are computed using a pooled regression of quantity demanded on four treatment dummies. Tests allow for arbitrary correlation of unobservables at the participant level. 
Table 4: Distribution of Quantity Demanded for Each Price

Panel A: Income Assignment Based on Rank

\begin{tabular}{c|cc|cc|cc|cc|c}
\hline $\begin{array}{c}\text { Price } \\
\text { (cents) }\end{array}$ & $\begin{array}{c}\text { Pub. } \\
30^{\text {th }}\end{array}$ & $\begin{array}{c}\text { Priv. } \\
30 \text { th }\end{array}$ & $\begin{array}{c}\text { Pub. } \\
50^{\text {th }}\end{array}$ & $\begin{array}{c}\text { Priv. } \\
50^{\text {th }}\end{array}$ & $\begin{array}{c}\text { Pub. } \\
70^{\text {th }}\end{array}$ & $\begin{array}{c}\text { Priv. } \\
70^{\text {th }}\end{array}$ & $\begin{array}{c}\text { Pub. } \\
90^{\text {th }}\end{array}$ & $\begin{array}{c}\text { Priv. } \\
90^{\text {th }}\end{array}$ & $\begin{array}{c}\text { Pub. }=\text { Priv. } \\
\text { p-value }\end{array}$ \\
\hline 20 & 2 & 0 & 5 & 2 & 12 & 4 & 35 & 10 & 0.007 \\
25 & 1 & 0 & 4 & 1 & 10 & 3 & 21 & 8 & 0.004 \\
30 & 1 & 0 & 3 & 0.5 & 8 & 2 & 20 & 10 & 0.007 \\
35 & 1 & 0 & 2 & 0 & 7 & 2 & 13 & 6 & 0.007 \\
40 & 0 & 0 & 1 & 0 & 6 & 1 & 11 & 5 & 0.061 \\
45 & 0 & 0 & 1 & 0 & 5 & 1 & 10 & 3 & 0.037 \\
50 & 0 & 0 & 1 & 0 & 4 & 1 & 9 & 4 & 0.035 \\
55 & 0 & 0 & 1 & 0 & 3 & 0 & 8 & 3 & 0.003 \\
60 & 0 & 0 & 0.5 & 0 & 3 & 0 & 8 & 1 & 0.003 \\
\hline
\end{tabular}

Panel B: Income Assignment is Random

\begin{tabular}{c|cc|cc|cc|cc|c}
\hline $\begin{array}{c}\text { Price } \\
\text { (cents) }\end{array}$ & $\begin{array}{c}\text { Pub. } \\
30^{\text {th }}\end{array}$ & $\begin{array}{c}\text { Priv. } \\
30^{\text {th }}\end{array}$ & $\begin{array}{c}\text { Pub. } \\
50^{\text {th }}\end{array}$ & $\begin{array}{c}\text { Priv. } \\
50^{\text {th }}\end{array}$ & $\begin{array}{c}\text { Pub. } \\
70^{\text {th }}\end{array}$ & $\begin{array}{c}\text { Priv. } \\
70^{\text {th }}\end{array}$ & $\begin{array}{c}\text { Pub. } \\
90^{\text {th }}\end{array}$ & $\begin{array}{c}\text { Priv. } \\
90^{\text {th }}\end{array}$ & $\begin{array}{c}\text { Pub. = Priv. } \\
\text { p-value }\end{array}$ \\
\hline 20 & 1 & 0 & 4 & 1 & 6 & 4 & 10 & 10 & 0.103 \\
25 & 0 & 0 & 3 & 0 & 5 & 2 & 8 & 8 & 0.048 \\
30 & 0 & 0 & 1 & 0 & 3 & 1 & 5 & 8 & 0.176 \\
35 & 0 & 0 & 0 & 0 & 2 & 1 & 4 & 8 & 0.296 \\
40 & 0 & 0 & 0 & 0 & 1 & 1 & 4 & 5 & 0.476 \\
45 & 0 & 0 & 0 & 0 & 1 & 0 & 2 & 4 & 0.310 \\
50 & 0 & 0 & 0 & 0 & 1 & 0 & 2 & 3 & 0.207 \\
55 & 0 & 0 & 0 & 0 & 1 & 0 & 2 & 2 & 0.365 \\
60 & 0 & 0 & 0 & 0 & 0 & 0 & 2 & 2 & 0.337 \\
\hline
\end{tabular}

Notes: P-values are from Wilcoxon tests of the equalities of distributions. 
Table 5: Effects of Visibility on Demanded

\begin{tabular}{|c|c|c|}
\hline Quantity demanded & (1) & (2) \\
\hline Public & $\begin{array}{c}0.01 \\
(0.69)\end{array}$ & $\begin{array}{l}-0.72 \\
(0.90)\end{array}$ \\
\hline Rank & $\begin{array}{c}0.19 \\
(0.82)\end{array}$ & $\begin{array}{c}0.10 \\
(0.90)\end{array}$ \\
\hline Public $\times$ Rank & $\begin{array}{l}3.04 * * \\
(1.29)\end{array}$ & $\begin{array}{c}3.49 * * \\
(1.42)\end{array}$ \\
\hline Female & & $\begin{array}{c}0.93 \\
(0.74)\end{array}$ \\
\hline High CRT & & $\begin{array}{l}1.33^{*} \\
(0.76)\end{array}$ \\
\hline Risk Aversion & & $\begin{array}{c}0.93 \\
(0.65)\end{array}$ \\
\hline Competitive Preferences & & $\begin{array}{l}-1.19 \\
(1.55)\end{array}$ \\
\hline Ate Chocolate Recently & & $\begin{array}{l}1.41 * \\
(0.78)\end{array}$ \\
\hline Ate Recently & & $\begin{array}{c}-1.22 * * \\
(0.61)\end{array}$ \\
\hline Age $21+$ & & $\begin{array}{c}0.04 \\
(0.84)\end{array}$ \\
\hline White & & $\begin{array}{l}-0.13 \\
(0.80)\end{array}$ \\
\hline African-American & & $\begin{array}{c}-1.96 * * \\
(0.93)\end{array}$ \\
\hline Undergraduate & & $\begin{array}{c}0.51 \\
(0.84)\end{array}$ \\
\hline Family Income $>\$ 120 \mathrm{~K}$ & & $\begin{array}{c}0.01 \\
(0.67)\end{array}$ \\
\hline Employed & & $\begin{array}{c}0.42 \\
(0.70)\end{array}$ \\
\hline Constant & $\begin{array}{c}1.75 * * * \\
(0.62)\end{array}$ & $\begin{array}{c}0.29 \\
(1.68) \\
\end{array}$ \\
\hline $\begin{array}{l}\text { Adjusted } R^{2} \\
N\end{array}$ & $\begin{array}{l}0.07 \\
1,296\end{array}$ & $\begin{array}{c}0.11 \\
1,296\end{array}$ \\
\hline
\end{tabular}

Notes: * significant at 0.10 , $* *$ significant at 0.05 , and $* * *$ significant at 0.01 level. Standard errors allow for arbitrary correlation of unobservables at the participant level. 
Table 6: Mediators of Conspicuous Consumption

\begin{tabular}{lccccccc}
\hline Quantity demanded & $(1)$ & $(2)$ & $(3)$ & $(4)$ & $(5)$ & $(6)$ & $(7)$ \\
\hline Public & $3.04^{* * *}$ & $3.17^{* * *}$ & $5.93^{* * *}$ & 0.61 & $2.03^{*}$ & $4.11^{* * *}$ & 2.74 \\
& $(1.09)$ & $(0.87)$ & $(1.28)$ & $(1.11)$ & $(1.09)$ & $(1.02)$ & $(2.07)$ \\
Public $\times$ Female & & & $-5.38^{* * *}$ & & & & $-3.79^{* *}$ \\
& & & $(1.58)$ & & & & $(1.71)$ \\
Public $\times$ High CRT & & & & $5.29^{* * *}$ & & & $3.93^{* *}$ \\
& & & & $(1.71)$ & & & $(1.92)$ \\
Public $\times$ Risk Aversion & & & & & 2.41 & & 1.24 \\
& & & & & $(1.87)$ & & $(1.74)$ \\
Public $\times$ Competitive Preferences & & & & & & $-5.34^{* *}$ & -0.67 \\
& & -0.21 & $2.39^{*}$ & -0.96 & -0.19 & -0.08 & 1.09 \\
Female & & $(1.35)$ & $(1.41)$ & $(1.25)$ & $(1.33)$ & $(1.33)$ & $(1.38)$ \\
& & 1.41 & $1.82^{*}$ & -1.37 & 1.39 & 1.31 & -0.40 \\
High CRT & & $(0.97)$ & $(0.94)$ & $(1.08)$ & $(1.00)$ & $(0.98)$ & $(1.13)$ \\
& & 0.99 & 0.84 & 0.54 & -0.16 & 0.79 & -0.07 \\
Risk Aversion & & $(0.85)$ & $(0.83)$ & $(0.85)$ & $(1.19)$ & $(0.83)$ & $(1.17)$ \\
Competitive Preferences & & -1.32 & -1.15 & -0.50 & -1.15 & 1.81 & -0.11 \\
& & $(2.23)$ & $(2.15)$ & $(2.13)$ & $(2.24)$ & $(2.75)$ & $(2.81)$ \\
Constant & $1.94 * * *$ & 2.68 & 1.91 & $4.78^{* *}$ & 3.21 & 1.80 & 3.86 \\
& $(0.54)$ & $(2.58)$ & $(2.39)$ & $(2.24)$ & $(2.73)$ & $(2.51)$ & $(2.41)$ \\
\hline Adjusted $R^{2}$ & 0.06 & 0.23 & 0.27 & 0.26 & 0.23 & 0.24 & 0.29 \\
$N$ & 648 & 648 & 648 & 648 & 648 & 648 & 648 \\
\hline
\end{tabular}

Notes: * significant at $0.10, * *$ significant at 0.05 , and $* * *$ significant at 0.01 level. Regressions of participant chocolate choices in the rank-private and rank-public treatments. All columns include test rank dummies. Standard errors allow for arbitrary correlation of unobservables at the participant level. 
Table 7: Conspicuous Consumption by Gender and CRT

\begin{tabular}{lc}
\hline Quantity demanded & $(1)$ \\
\hline Public & $3.50^{* *}$ \\
& $(1.64)$ \\
Public $\times$ Female & $-4.69^{* *}$ \\
& $(1.85)$ \\
Public $\times$ High CRT & 3.27 \\
& $(2.30)$ \\
Public $\times$ Female $\times$ High CRT & 1.82 \\
& $(3.31)$ \\
Female $\times$ High CRT & 1.75 \\
& $(3.14)$ \\
Female & 0.01 \\
& $(1.70)$ \\
High CRT & -1.61 \\
& $(1.77)$ \\
Constant & $4.95^{* *}$ \\
& $(2.24)$ \\
\hline Adjusted $R^{2}$ & 0.29 \\
$N$ & 648 \\
\hline
\end{tabular}

Notes: ** significant at 0.05 level. Regressions of participant chocolate choices in the rank-private and rank-public treatments. Includes test rank dummies. Standard errors allow for arbitrary correlation of unobservables at the participant level. 
Table 8: Mean Decision Welfare

Panel A: Overall

\begin{tabular}{ccccc}
\hline $\begin{array}{c}\text { Chocolate } \\
\text { Price }\end{array}$ & $\begin{array}{c}\text { Rank-Private } \\
\text { Demand }\end{array}$ & $\begin{array}{c}\text { Consumer } \\
\text { Surplus }\end{array}$ & Welfare Loss & $\begin{array}{c}\text { Welfare Loss / } \\
\text { Consumer Surplus }\end{array}$ \\
\hline$\$ 0.60$ & 0.4 & $\$ 0.01$ & $\$ 0.25$ & 25 \\
$\$ 0.50$ & 1.0 & $\$ 0.08$ & $\$ 0.23$ & 2.9 \\
$\$ 0.40$ & 1.8 & $\$ 0.21$ & $\$ 0.21$ & 1.0 \\
$\$ 0.30$ & 2.6 & $\$ 0.42$ & $\$ 0.35$ & 0.8 \\
$\$ 0.20$ & 4.3 & $\$ 0.76$ & $\$ 0.49$ & 0.7 \\
\hline
\end{tabular}

Panel B: Men

\begin{tabular}{ccccc}
\hline $\begin{array}{c}\text { Chocolate } \\
\text { Price }\end{array}$ & $\begin{array}{c}\text { Rank-Private } \\
\text { Demand }\end{array}$ & $\begin{array}{c}\text { Consumer } \\
\text { Surplus }\end{array}$ & Welfare Loss & $\begin{array}{c}\text { Welfare Loss / } \\
\text { Consumer Surplus }\end{array}$ \\
\hline$\$ 0.60$ & 0.4 & $\$ 0.01$ & $\$ 0.52$ & 52 \\
$\$ 0.50$ & 0.7 & $\$ 0.12$ & $\$ 0.67$ & 5.6 \\
$\$ 0.40$ & 1.3 & $\$ 0.22$ & $\$ 0.71$ & 3.2 \\
$\$ 0.30$ & 1.6 & $\$ 0.36$ & $\$ 0.97$ & 2.7 \\
$\$ 0.20$ & 2.9 & $\$ 0.57$ & $\$ 1.00$ & 1.7 \\
\hline
\end{tabular}

Panel C: Women

\begin{tabular}{ccccc}
\hline $\begin{array}{c}\text { Chocolate } \\
\text { Price }\end{array}$ & $\begin{array}{c}\text { Rank-Private } \\
\text { Demand }\end{array}$ & $\begin{array}{c}\text { Consumer } \\
\text { Surplus }\end{array}$ & Welfare Loss & $\begin{array}{c}\text { Welfare Loss / } \\
\text { Consumer Surplus }\end{array}$ \\
\hline$\$ 0.60$ & 0.4 & $\$ 0.00$ & $\$ 0.13$ & -- \\
$\$ 0.50$ & 0.8 & $\$ 0.01$ & $\$ 0.04$ & 4.3 \\
$\$ 0.40$ & 2.2 & $\$ 0.17$ & $\$ 0.01$ & 0.05 \\
$\$ 0.30$ & 3.7 & $\$ 0.47$ & $\$ 0.01$ & 0.03 \\
$\$ 0.20$ & 5.8 & $\$ 0.94$ & $\$ 0.07$ & 0.07 \\
\hline
\end{tabular}

Notes: Calculations based on numerical integration of estimated demand curves from the rankprivate and rank-public treatments. See Section 3.5 for an explanation. 
Table 9: Adjusted Participant Mood by Treatment

Panel A: Overall

\begin{tabular}{lccc}
\hline & Random & Rank & $H_{0}:$ Rank $=$ Random \\
\hline Private & 5.21 & 4.38 & $\mathrm{p}=0.05$ \\
Public & 5.16 & 5.14 & $\mathrm{p}=0.95$ \\
\hline $\mathrm{H}_{0}:$ Public = Private & $\mathrm{p}=0.88$ & $\mathrm{p}=0.04$ & \\
\hline
\end{tabular}

Panel B: Men

\begin{tabular}{lccc}
\hline & Random & Rank & $H_{0}:$ Rank $=$ Random \\
\hline Private & 5.39 & 5.02 & $\mathrm{p}=0.51$ \\
Public & 5.91 & 4.90 & $\mathrm{p}=0.04$ \\
\hline $\mathrm{H}_{0}:$ Public = Private & $\mathrm{p}=0.16$ & $\mathrm{p}=0.79$ & \\
\hline
\end{tabular}

Panel C: Women

\begin{tabular}{lccc}
\hline & Random & Rank & $H_{0}:$ Rank $=$ Random \\
\hline Private & 4.95 & 4.03 & $\mathrm{p}=0.09$ \\
Public & 3.97 & 5.47 & $\mathrm{p}=0.01$ \\
\hline $\mathrm{H}_{0}:$ Public $=$ Private & $\mathrm{p}=0.11$ & $\mathrm{p}<0.01$ & \\
\hline
\end{tabular}

Notes: Mood is measured on a seven point scale ranging from very bad (1) to very good (7). Adjusted means are calculated from a regression of mood on treatment dummies and controls for actual chocolate price, income, and payouts from the risk aversion and social preferences elicitations. The adjustment assigns each participant the mean level of income, payouts, and chocolate price. 


\section{Appendix A - Instructions for the Rank-Public Treatment}

\section{PART 1 - EXERCISE}

In this exercise you will be asked to answer three questions. Below are three items that vary in difficulty. Answer as many as you can.

1. A bat and a ball cost $\$ 1.10$ in total. The bat costs $\$ 1.00$ more than the ball.

How much does the ball cost? cents

2. It takes 5 machines 5 minutes to make 5 widgets.

How long does it take 100 machines to make 100 widgets? minutes

3. In a lake, there is a patch of lily pads. Every day, the patch doubles in size. It takes 48 days for the patch to cover the entire lake.

How long does it take for the patch to cover half of the lake? days

\section{PART 2 - COGNITIVE TEST}

You will now take a 30-minute cognitive test containing 20 questions. You may use the margins of this booklet work out your answer if needed. You may ONLY use pencil, paper, and calculator provided. No other aids are permitted.

Please use the attached bubble sheet to record your answers. All questions have the following format:

Who is the current President of the United States?
A. Mitt Romney
B. Bill Clinton
C. Barack Obama
D. George W. Bush
E. David Cameron

To correctly answer this example question, you would fill in bubble $\mathrm{C}$ in line 0 .

You will gain one point for each correct answer and lose one point for each incorrect answer. There is no penalty for leaving a question blank. Please try to get as many points as you can.

You will have 30 minutes to work on the questions. You may not be able to finish all the questions in this time.

\section{COGNITIVE TEST SCORE AND RANK}

Your score on the cognitive test is Your rank among today's test takers is This table shows how many dollars you get based on your rank in the cognitive test. 


\begin{tabular}{|l|l|}
\hline Rank & Points \\
\hline 1 & $\$ 13.25$ \\
\hline 2 & $\$ 12.50$ \\
\hline 3 & $\$ 11.75$ \\
\hline 4 & $\$ 11.00$ \\
\hline 5 & $\$ 10.25$ \\
\hline 6 & $\$ 9.50$ \\
\hline 7 & $\$ 8.75$ \\
\hline 8 & $\$ 8.00$ \\
\hline 9 & $\$ 7.25$ \\
\hline 10 & $\$ 6.50$ \\
\hline 11 & $\$ 5.75$ \\
\hline 12 & $\$ 5.00$ \\
\hline
\end{tabular}

\section{PART 3 - CHOCOLATE SELECTION}

You have an opportunity to purchase Godiva chocolate truffles using your earnings. Godiva is considered to be a premium chocolate. The chocolates are individually wrapped. Each weighs about $1 / 3$ ounce. You will be able to buy as many chocolates as you want as long as the total cost is less than your earnings.

The price of squares will be between $\$ 0.20$ and $\$ 0.60$ per chocolate and will be determined by the roll of a ten-sided die. You will indicate how many chocolates you would like for each price that may be randomly selected by the die. In this way you may choose to purchase different amounts depending on whether the chocolate is relatively expensive or inexpensive.

After you have completed your choices, the actual price will be determined by the roll of a tensided die. Once the actual price is determined, each of you will come up to the board and write out your first and last name, your ID, the number of chocolates you purchased, the total amount you spent on chocolate, and your preference for dark or milk chocolate. This will help us package the chocolate for you.

Use the following table to record your decisions:

\begin{tabular}{|l|l|l|l|}
\hline $\begin{array}{l}\text { Roll of } \\
\text { die }\end{array}$ & Price & $\begin{array}{l}\text { How many pieces would you } \\
\text { like to purchase at this price? }\end{array}$ & $\begin{array}{l}\text { Total spent on chocolate at this price }= \\
\text { Price per piece } \times \text { number of pieces. }\end{array}$ \\
\hline 1 & $\$ 0.20$ & & $\$ 0.20 \times$ \\
\hline 2 & $\$ 0.25$ & & $\$ 0.25 \times$ \\
\hline 3 & $\$ 0.30$ & & $\$ 0.30 \times$ \\
\hline 4 & $\$ 0.35$ & & $\$ 0.35 \times$ \\
\hline 5 & $\$ 0.40$ & & $\$ 0.40 \times$ \\
\hline 6 & $\$ 0.45$ & & $\$ 0.45 \times$ \\
\hline 7 & $\$ 0.50$ & & $\$ 0.50 \times$ \\
\hline 8 & $\$ 0.55$ & & $\$ 0.55 \times$ \\
\hline 9 & $\$ 0.60$ & & $\$ 0.60 \times$ \\
\hline
\end{tabular}




\section{PART 4 - DECISION PROBLEMS}

In this part of the experiment, you will be asked to make a series of choices in decision problems. How much money you receive will depend partly on chance and partly on the choices you make.

You will see a table with 20 lines. You will state whether you prefer Option A or Option B in each line. You should think of each line as a separate decision you need to make. At the end of the experiment, we will draw a card from a deck of cards numbered $1,2, \ldots, 20$. The number on the card chosen indicates which line in this part will be paid out. You will be paid according to the option you selected on that line.

In the table, option A always offers a $50 \%$ chance to get $\$ 10$ and a $50 \%$ chance to get nothing. To determine the earnings for people who choose option A, after drawing the card that determines which line will be paid, we will randomly draw a ball from a bag containing ten orange balls and ten white balls. That means that when we draw a ball, there is a 50\% chance that it is white and a $50 \%$ chance that it is orange. If the drawn ball is white and you selected option A in that decision, you will get the $\$ 10$, otherwise you will get $\$ 0$.

Use the following table to record your decisions:

\begin{tabular}{|c|c|c|c|c|}
\hline $\begin{array}{l}\text { Decision } \\
\text { Number }\end{array}$ & \multicolumn{2}{|c|}{ Option A } & Option B & $\begin{array}{c}\text { Choose } \\
A \text { or B }\end{array}$ \\
\hline 1 & $\$ 10.00$ with $50 \%$ chance & $\$ 0.00$ with $50 \%$ chance & $\$ 0.50$ for sure & \\
\hline 2 & $\$ 10.00$ with $50 \%$ chance & $\$ 0.00$ with $50 \%$ chance & $\$ 1.00$ for sure & \\
\hline 3 & $\$ 10.00$ with $50 \%$ chance & $\$ 0.00$ with $50 \%$ chance & $\$ 1.50$ for sure & \\
\hline 4 & $\$ 10.00$ with $50 \%$ chance & $\$ 0.00$ with $50 \%$ chance & $\$ 2.00$ for sure & \\
\hline 5 & $\$ 10.00$ with $50 \%$ chance & $\$ 0.00$ with $50 \%$ chance & $\$ 2.50$ for sure & \\
\hline 6 & $\$ 10.00$ with $50 \%$ chance & $\$ 0.00$ with $50 \%$ chance & $\$ 3.00$ for sure & \\
\hline 7 & $\$ 10.00$ with $50 \%$ chance & $\$ 0.00$ with $50 \%$ chance & $\$ 3.50$ for sure & \\
\hline 8 & $\$ 10.00$ with $50 \%$ chance & $\$ 0.00$ with $50 \%$ chance & $\$ 4.00$ for sure & \\
\hline 9 & $\$ 10.00$ with $50 \%$ chance & $\$ 0.00$ with $50 \%$ chance & $\$ 4.50$ for sure & \\
\hline 10 & $\$ 10.00$ with $50 \%$ chance & $\$ 0.00$ with $50 \%$ chance & $\$ 5.00$ for sure & \\
\hline 11 & $\$ 10.00$ with $50 \%$ chance & $\$ 0.00$ with $50 \%$ chance & $\$ 5.50$ for sure & \\
\hline 12 & $\$ 10.00$ with $50 \%$ chance & $\$ 0.00$ with $50 \%$ chance & $\$ 6.00$ for sure & \\
\hline 13 & $\$ 10.00$ with $50 \%$ chance & $\$ 0.00$ with $50 \%$ chance & $\$ 6.50$ for sure & \\
\hline 14 & $\$ 10.00$ with $50 \%$ chance & $\$ 0.00$ with $50 \%$ chance & $\$ 7.00$ for sure & \\
\hline 15 & $\$ 10.00$ with $50 \%$ chance & $\$ 0.00$ with $50 \%$ chance & $\$ 7.50$ for sure & \\
\hline 16 & $\$ 10.00$ with $50 \%$ chance & $\$ 0.00$ with $50 \%$ chance & $\$ 8.00$ for sure & \\
\hline 17 & $\$ 10.00$ with $50 \%$ chance & $\$ 0.00$ with $50 \%$ chance & $\$ 8.50$ for sure & \\
\hline 18 & $\$ 10.00$ with $50 \%$ chance & $\$ 0.00$ with $50 \%$ chance & $\$ 9.00$ for sure & \\
\hline 19 & $\$ 10.00$ with $50 \%$ chance & $\$ 0.00$ with $50 \%$ chance & $\$ 9.50$ for sure & \\
\hline 20 & $\$ 10.00$ with $50 \%$ chance & $\$ 0.00$ with $50 \%$ chance & $\$ 10.00$ for sure & \\
\hline
\end{tabular}




\section{PART 5 - DECISION PROBLEMS}

In this part of the experiment, you will be asked to make a series of choices in decision problems. You will see a table with 12 lines. You will state whether you prefer Option A or Option B in each line. You should think of each line as a separate decision you need to make. However, only one line will be the 'line that counts' and will be paid out. In particular, at the end of the experiment, we will draw a card from a deck of cards numbered $1,2, \ldots, 12$. The number on the card chosen indicates which line in that part will be paid out.

For each line in the table on the next page, please state whether you prefer option A or option B. Notice that there are a total of $\mathbf{1 2}$ lines in the table - you should think of each line as a separate decision you need to make.

These decisions affect both your own earnings and those of another participant in the experiment today. All participants have randomly and anonymously being divided into pairs according to subject number.

Your earnings for the selected line depend on which option you chose: if you chose option A in that line, you will receive $\mathbf{\$ 3 . 0 0}$ and the other participant who will be matched with you will also receive \$3.00. If you chose option B in that line, you and the other participant will receive earnings as indicated in the table for that specific line. For example, if you chose B in line 2 and this line is selected for payment, you will receive $\mathbf{\$ 3 . 0 0}$ and the other participant will receive $\mathbf{\$ 2 . 0 0}$. Similarly, if you chose B in line 3 and this line is selected for payment, you will receive $\mathbf{\$ 3 . 0 0}$ and the other participant will receive $\mathbf{\$ 1 . 5 0}$.

After you have completed all your choices we will draw a card from a deck of cards numbered 1, $2, \ldots, 12$ to determine which line is going to be paid. Within each pair, one participant has the higher and the other the lower subject number. We will then draw a ball from a bag containing 10 orange and 10 white balls. The ball color determines whether the decision of the higher (orange) or lower (white) subject number will be implemented. If your decision is chosen to be implemented, then the earnings to you and the other participant will be determined according to your choice of A or B. If the other participant's decision is chosen to be implemented, then the earnings will be determined according to the other participant choice of A or B.

Use the following table to record your decisions:

\begin{tabular}{|l||l||l||c|}
\hline $\begin{array}{l}\text { Decision } \\
\text { Number }\end{array}$ & $\begin{array}{c}\text { Option } \mathrm{A} \\
\text { (you, the other participant) }\end{array}$ & $\begin{array}{c}\text { Option } \mathrm{B} \\
\text { (you, the other participant) }\end{array}$ & $\begin{array}{c}\text { Choose } \\
\text { A or } \mathrm{B}\end{array}$ \\
\hline 1 & $\$ 3.00$ to you, $\$ 3.00$ to other & $\$ 3.00$ to you, $\$ 2.50$ to other & \\
\hline 2 & $\$ 3.00$ to you, $\$ 3.00$ to other & $\$ 3.00$ to you, $\$ 2.00$ to other & \\
\hline 3 & $\$ 3.00$ to you, $\$ 3.00$ to other & $\$ 3.00$ to you, $\$ 1.50$ to other & \\
\hline 4 & $\$ 3.00$ to you, $\$ 3.00$ to other & $\$ 2.50$ to you, $\$ 2.00$ to other & \\
\hline 5 & $\$ 3.00$ to you, $\$ 3.00$ to other & $\$ 2.50$ to you, $\$ 1.50$ to other & \\
\hline 6 & $\$ 3.00$ to you, $\$ 3.00$ to other & $\$ 2.50$ to you, $\$ 1.00$ to other & \\
\hline 7 & $\$ 3.00$ to you, $\$ 3.00$ to other & $\$ 3.00$ to you, $\$ 3.50$ to other & \\
\hline 8 & $\$ 3.00$ to you, $\$ 3.00$ to other & $\$ 3.00$ to you, $\$ 4.00$ to other & \\
\hline
\end{tabular}




\begin{tabular}{|l||l||l||l|}
\hline 9 & $\$ 3.00$ to you, $\$ 3.00$ to other & $\$ 3.00$ to you, $\$ 4.50$ to other & \\
\hline 10 & $\$ 3.00$ to you, $\$ 3.00$ to other & $\$ 3.50$ to you, $\$ 4.00$ to other & \\
\hline 11 & $\$ 3.00$ to you, $\$ 3.00$ to other & $\$ 3.50$ to you, $\$ 4.50$ to other & \\
\hline 12 & $\$ 3.00$ to you, $\$ 3.00$ to other & $\$ 3.50$ to you, $\$ 5.00$ to other & \\
\hline
\end{tabular}

After you have completed your decisions, please fill out the bubble sheet attached to this booklet with your responses for each line, indicating whether you chose A or B. 


\section{Appendix B - Additional Tables}

Table B1: Participant Mood and Experiment Outcomes

\begin{tabular}{|c|c|c|}
\hline & (1) & (2) \\
\hline Income (rank or random) & $\begin{array}{c}0.17 * * * \\
(0.05)\end{array}$ & $\begin{array}{c}0.16 * * * \\
(0.05)\end{array}$ \\
\hline Actual Chocolate Price & $\begin{array}{l}0.02 * * \\
(0.01)\end{array}$ & $\begin{array}{l}0.02 * * \\
(0.01)\end{array}$ \\
\hline Payout from Risk Aversion & $\begin{array}{c}0.01 \\
(0.02)\end{array}$ & $\begin{array}{c}0.01 \\
(0.02)\end{array}$ \\
\hline Payout from Competitive Preferences & $\begin{array}{c}0.18 \\
(0.21)\end{array}$ & $\begin{array}{c}0.15 \\
(0.23)\end{array}$ \\
\hline Female & & $\begin{array}{c}-0.65 * * \\
(0.26)\end{array}$ \\
\hline High CRT & & $\begin{array}{l}0.49 * \\
(0.25)\end{array}$ \\
\hline More Risk Averse & & $\begin{array}{c}0.17 \\
(0.23)\end{array}$ \\
\hline Competitive Preferences & & $\begin{array}{c}0.05 \\
(0.54)\end{array}$ \\
\hline Ate Chocolate Recently & & $\begin{array}{l}-0.01 \\
(0.22)\end{array}$ \\
\hline Ate Recently & & $\begin{array}{c}0.04 \\
(0.25)\end{array}$ \\
\hline Age $21+$ & & $\begin{array}{c}0.00 \\
(0.31)\end{array}$ \\
\hline White & & $\begin{array}{l}-0.27 \\
(0.27)\end{array}$ \\
\hline African-American & & $\begin{array}{l}-0.76^{*} \\
(0.41)\end{array}$ \\
\hline Undergraduate & & $\begin{array}{l}-0.28 \\
(0.40)\end{array}$ \\
\hline Family Income $>\$ 120 \mathrm{~K}$ & & $\begin{array}{l}-0.08 \\
(0.24)\end{array}$ \\
\hline Employed & & $\begin{array}{c}0.33 \\
(0.24)\end{array}$ \\
\hline Constant & $\begin{array}{l}2.04^{*} \\
(1.06)\end{array}$ & $\begin{array}{l}2.60 * * \\
(1.17)\end{array}$ \\
\hline $\begin{array}{l}\text { Adjusted } R^{2} \\
N\end{array}$ & $\begin{array}{l}0.11 \\
142\end{array}$ & $\begin{array}{c}0.14 \\
142\end{array}$ \\
\hline
\end{tabular}

Notes: * significant at $0.10, * *$ significant at 0.05 , and $* * *$ significant at 0.01 level. Standard errors corrected for heteroskedasticity. 
Table B2: Unadjusted Participant Mood by Treatment

Panel A: Overall

\begin{tabular}{lccc}
\hline & Random & Rank & $H_{0}:$ Rank $=$ Random \\
\hline Private & 5.11 & 4.43 & $\mathrm{p}=0.05$ \\
Public & 5.25 & 5.12 & $\mathrm{p}=0.68$ \\
\hline $\mathrm{H}_{0}:$ Public = Private & $\mathrm{p}=0.69$ & $\mathrm{p}=0.05$ & \\
\hline
\end{tabular}

Panel B: Men

\begin{tabular}{lccc}
\hline & Random & Rank & $H_{0}:$ Rank $=$ Random \\
\hline Private & 5.25 & 5.28 & $\mathrm{p}=0.95$ \\
Public & 5.78 & 4.94 & $\mathrm{p}=0.06$ \\
\hline $\mathrm{H}_{0}:$ Public = Private & $\mathrm{p}=0.15$ & $\mathrm{p}=0.48$ & \\
\hline
\end{tabular}

Panel C: Women

\begin{tabular}{lccc}
\hline & Random & Rank & $H_{0}:$ Rank $=$ Random \\
\hline Private & 4.94 & 3.56 & $\mathrm{p}=0.01$ \\
Public & 4.65 & 5.29 & $\mathrm{p}=0.16$ \\
\hline $\mathrm{H}_{0}:$ Public = Private & $\mathrm{p}=0.60$ & $\mathrm{p}<0.01$ & \\
\hline
\end{tabular}

Notes: Mood is measured on a seven point scale ranging from very bad (1) to very good (7). 
Table B3: Mean Quantity Demanded by Treatment and Gender

\begin{tabular}{lccc}
\multicolumn{4}{c}{ Panel A: Men } \\
& Random & Rank & $\begin{array}{c}H_{0}: \text { Random } \\
=\text { Rank }\end{array}$ \\
\hline Private & 0.77 & 1.36 & $\mathrm{p}=0.41$ \\
Public & 1.97 & 6.48 & $\mathrm{p}<0.01$ \\
\hline $\mathrm{H}_{0}:$ Public $=$ Private & $\mathrm{p}=0.04$ & $\mathrm{p}<0.01$ & \\
\hline
\end{tabular}

Panel B: Women

\begin{tabular}{lccc}
\hline & Random & Rank & $\begin{array}{c}H_{0}: \text { Random } \\
=\text { Rank }\end{array}$ \\
\hline Private & 2.97 & 2.51 & $\mathrm{p}=0.77$ \\
Public & 1.51 & 3.46 & $\mathrm{p}=0.08$ \\
\hline $\mathrm{H}_{0}:$ Public $=$ Private & $\mathrm{p}=0.28$ & $\mathrm{p}=0.48$ & \\
\hline
\end{tabular}

Notes: Means for each treatment are computed by averaging over all potential prices. The tests of the null hypotheses are computed using a pooled regression of quantity demanded on four treatment dummies. Tests allow for arbitrary correlation of unobservables at the participant level. 
Table B4: Differential Effects by Test Rank when Income Assigned by Rank

\begin{tabular}{lcc}
\hline & $\begin{array}{c}\text { Income Share Spent } \\
\text { on Chocolate }\end{array}$ & $\begin{array}{c}\text { Participant } \\
\text { Mood }\end{array}$ \\
\hline Public & $(1)$ & $(2)$ \\
Public $\times$ Test Rank $>8$ & $0.11^{* *}$ & 0.13 \\
& $(0.05)$ & $(0.65)$ \\
Public $\times$ Female & $0.32^{*}$ & -0.54 \\
Public $\times$ Test Rank $>8 \times$ Female & $(0.18)$ & $(1.15)$ \\
Test Rank $>8$ & -0.09 & $1.58^{* *}$ \\
Female & $(0.06)$ & $(0.77)$ \\
Test Rank $>8 \times$ Female & -0.23 & 1.06 \\
Constant & $(0.21)$ & $(1.52)$ \\
& -0.01 & -0.71 \\
& $(0.03)$ & $(0.98)$ \\
Adjusted $\mathrm{R}^{2}$ & 0.00 & $-1.52^{* * *}$ \\
$N$ & $(0.03)$ & $(0.49)$ \\
& 0.12 & 0.12 \\
& $(0.08)$ & $(1.22)$ \\
\end{tabular}

Notes: * significant at $0.10, * *$ significant at 0.05 , and $* * *$ significant at 0.01 level. Column (1) is a regression of the share of income spent on chocolate in the rank-private and rank-public treatments. Column (2) is a regression of participant mood and includes controls for chocolate price, and payouts from the risk aversion and social preferences elicitations that are not shown in the table. Standard errors allow for arbitrary correlation of unobservables at the participant level. 